This item was submitted to Loughborough's Research Repository by the author.

Items in Figshare are protected by copyright, with all rights reserved, unless otherwise indicated.

\title{
A review of the reclaiming of rubber waste and recent work on the recycling of ethylene-propylene-diene rubber waste
}

PLEASE CITE THE PUBLISHED VERSION

http://dx.doi.org/10.5254/rct.15.84850

\section{PUBLISHER}

(c) American Chemical Society

\section{VERSION}

AM (Accepted Manuscript)

\section{PUBLISHER STATEMENT}

This work is made available according to the conditions of the Creative Commons Attribution-NonCommercialNoDerivatives 4.0 International (CC BY-NC-ND 4.0) licence. Full details of this licence are available at: https://creativecommons.org/licenses/by-nc-nd/4.0/

\section{LICENCE}

CC BY-NC-ND 4.0

\section{REPOSITORY RECORD}

Movahed, Saeed Ostad, Ali Ansarifar, and Sara Estagy. 2016. "A Review of the Reclaiming of Rubber Waste and Recent Work on the Recycling of Ethylene-propylene-diene Rubber Waste". figshare. https://hdl.handle.net/2134/21474. 


\title{
A review of the reclaiming of rubber waste and recent work on the recycling of ethylene-propylene-diene rubber waste
}

\author{
Saeed Ostad Movahed*, Ali Ansarifar**, Sara Estagy* \\ * Polymer group, Faculty of Sciences, Ferdowsi University of Mashhad, Mashhad, Iran \\ ** Department of Materials, Loughborough University, Loughborough, Leicestershire, \\ LE11 3TU, UK
}

\begin{abstract}
Rubbers do not decompose easily and therefore disposal of rubber waste is a serious environmental concern. Raw material costs, diminishing natural resources, and the growing awareness of environmental issues and sustainability have made rubber recycling a major area of concern. Reclaiming and recycling rubber waste is a major scientific and technological challenge facing rubber scientists today. This paper reviews a number of important areas related to the reclaiming, characterizing, testing and recycling of rubber waste. These include: chemical and microbial devulcanization with particular emphasis on main chain scission and kinetics of chemical devulcanization reactions; the cutting-edge techniques for reclaiming devulcanized rubber waste by the action of large shearing forces, heat and chemical agents: and analytical techniques and methods for characterizing composition and testing of devulcanized rubber waste, respectively. In addition, some aspects of the recycling of devulcanized ethylene-propylenediene rubber (EPDM) waste will be reported. EPDM is used extensively in automotive components world-wide and recycling the rubber at the end of its useful service life is of major importance to manufacturers of automotive components.
\end{abstract}

keywords: Ethylene-propylene diene rubber; Devulcanization kinetics; Devulcanization techniques; Revulcanization kinetics; Revulcanization techniques Chain scission; Characterization; Recycling 
1. Introduction 3

2. A review of recycling technology of scrap rubber 5

2.1. Background to regeneration/devulcanization of scrap rubber 5

2.2. A survey of important techniques and processes related to regeneration/devulcanization of scrap rubber $\quad 5$

3. Chemical and microbial devulcanization of rubber waste 9

4. Kinetics of chemical vulcanization of rubber and chemical devulcanization of scrap 11 rubber

5. Kinetics of chemical revulcanization of devulcanized scrap rubber

6. Techniques for reclaiming EPDM rubber waste 14

6.1. Autoclave 14

6.2. Microwave heating $\quad 15$

6.3. Twin screw extruder and internal mixers 17

7. Methods for characterizing and testing of vulcanized rubber applied to revulcanized $\begin{array}{ll}\text { EPDM scrap rubber } & 18\end{array}$

7.1. Swelling test $\quad 18$

7.2. Chain scission in a polymer network 20

7.3. Thermogravimetry analysis (TGA) in determining the waste rubber 20 composition

7.4. Solid-State H neutron mass spectroscopy 21

7.5. Differential scanning calorimeter (DSC) 21

7.6. Atomic absorption spectroscopy, ICP-OES, and CHNS analysis 22

8. Some aspects of the recycling and analytical testing of devulcanized EPDM rubber 22 waste

$\begin{array}{ll}\text { 9. Summary } & 25\end{array}$

$\begin{array}{ll}\text { 10. Conclusions } & 27\end{array}$

11. References 28 


\section{Introduction}

One of the problems that humanity faces in the $21^{\text {st }}$ century is waste disposal management. Rubbers are used in many applications such as tires, window seals, engine mountings, hoses, and isolation bearings. Eventually, these articles must be disposed of or scrapped at the end of their useful service lives. Reclaiming and recycling of waste rubber has important implications for the protection of the environment, conservation of energy, re-use with or in place of virgin rubber, costs reduction, and modification of the processing behavior of rubber compounds. ${ }^{1}$ These topics will be examined briefly here.

a) Protection of the environment: The environmental pollution caused by the disposal of waste rubber is getting increasing serious. For example, discarded old tires on open grounds are breeding places for mosquitoes and diseases which spread infections such as encephalitis and malaria. In addition, when tire dumps catch fire, they produce toxic fumes which are very harmful to the environment. ${ }^{1}$

b) Conservation of energy: Raw polymers and chemicals used to manufacture rubber goods are mostly petroleum derivatives. For example, more than $70 \%$ of the raw materials used to manufacture synthetic rubbers is made from petroleum. Moreover, waste rubber is a high value fuel with a calorific value of roughly $33000 \mathrm{~kJ} / \mathrm{kg}$, which is the highest value in the industrial waste sector similar to that of coal. ${ }^{1}$

c) Re-use with or in place of virgin rubber: Reclaimed waste rubber is used with raw virgin rubber or as replacement for it in many industrial rubber articles. For instance, shredded rubber is used in asphalt and children play grounds.

\section{d) Costs reduction and modification of the processing behavior of rubber compounds}

One of the major problems until now has been the limited use of waste rubber in real recycling loops, i.e., reuse in new rubber products. Improvement of the properties of waste rubber by developing a more selective breakdown process is an important issue and a global challenge. ${ }^{2}$

Rubber recycling techniques and science continue developing, aiming at the reutilization of waste rubber as close as possible to its virgin form. This type of recycling method where rubber is re-used like in its virgin form is called devulcanization or reclaiming. ASTM STP $184 \mathrm{~A}^{3}$ 
defines devulcanization as "a combination of depolymerization, oxidation, and increased plasticity” because each of these processes usually occurs during reclamation. In fact, devulcanization is the reverse of vulcanization. In sulfur vulcanization, the formation of both CS and S-S bonds takes place, and it is thus expected that during devulcanization, only C-S and S-S bonds cleavage should occur. In reality, in an ideal devulcanization process, crosslinks should be broken without main-chain scission. Figure 1 shows the difference in the molecular structure of virgin raw rubber, vulcanized rubber and devulcanized rubber. ${ }^{4}$

The energies required to break monosulfidic C-S , polysulfidic S-S and C-C bonds are 270, 240 and $345 \mathrm{~kJ} / \mathrm{mol}$, respectively. ${ }^{5}$ Hence, caution should be exercised during devulcanization as much as possible to avoid $\mathrm{C}-\mathrm{C}$ bonds cleavage. Cleavage of $\mathrm{C}-\mathrm{C}$ bonds weakens mechanical properties of the re-vulcanized waste rubber.

Ethylene-propylene-diene rubber (EPDM) (Fig. 2) was first introduced in the USA in limited commercial quantities in $1962 .{ }^{6}$ EPDM is a copolymer of ethylene and propylene with a diene monomer which introduces unsaturation sites or double bonds into the macromolecule. Currently, EPDM is the fastest-growing general purpose rubber. This is because EPDM has excellent properties such as high resistance to ozone and oxygen and ability to tolerate high loading of solid filler. In automotive applications, about $3 \mathrm{wt} \%$ of the total weight of a vehicle is made of non-tire rubber products, namely weather-strips, hoses, vibration insulators, and miscellaneous parts. ${ }^{7}$ EPDM was the preferred choice in this study because it is used extensively in automotive components world-wide and recycling the rubber at the end of its useful service life is of major importance to manufacturers of automotive.

This paper reviews a number of important areas related to the reclaiming, characterizing, testing and recycling of rubber waste. These include: chemical and microbial devulcanization with particular emphasis on main chain scission and kinetics of chemical devulcanization reactions; the cutting-edge techniques for reclaiming devulcanized rubber waste by the action of large shearing forces, heat and chemical agents: and analytical techniques and methods for characterizing composition and testing of devulcanized rubber waste, respectively. In addition, some aspects of the recycling of devulcanized ethylene-propylene-diene rubber (EPDM) waste will be reported. 
2. A review of recycling technology of scrap rubber

\subsection{Background to regeneration/devulcanization of scrap rubber}

There are significant economic and environmental reasons to develop recycling technologies and recycle scrap rubber for further industrial use. In recent years, outstanding work has been carried out to recycle waste rubber. Myhre and MacKillp ${ }^{8-15}$ reviewed reclaiming, regeneration/devulcanization of scrap rubber in detail. They identified at least three important processes for reclaiming scarp rubber. They were thermal process, followed by the heater/pan and the alkali digester process, which worked well to reclaim natural rubber. The alkali digester process, was similar to the heater process but performed in a jacketed autoclave. The method of reclaiming rubber utilizing aqueous alkaline solutions was eventually phased out because of environmental pollution hazard. Other methods include grinding and size reduction. The major processes for making crumb rubber are mechanical grinding at ambient temperature, cryogenic grinding and wet grinding. Ambient grinding is carried out on a two-roll cracker-type mill. ${ }^{16}$ This is a very elaborate process which involves coarse crumb sizing, ultrafine sizing, metal separation, fiber separation, bagging and weighing. The process reduces large pieces of scrap rubber to size in the range of 10-40 mesh in the first stage and then to crumbs size of 80 mesh in the final stage ${ }^{17}$ Cryogenic grinding first cools shredded rubber pieces less than 3 inches in size with liquid nitrogen so the rubber is frozen. ${ }^{18}$ The frozen shreds are then passed through an impact mill to shatter and ground it into finer mesh grinds. The crumb is then dried fibers and metal separated and then classified into the various mesh sizes. Wet grinding uses a series of grinding wheels with water sprayed continuously to ensure cooling of the crumb. Water is then separated from the crumb, dried and then the physical properties such as bulk density, particle size and particle size distribution measured. ${ }^{19-24}$

\subsection{A survey of important techniques and processes related to regeneration/devulcanization of} scrap rubber

Devulcanization of scrap rubber has been an extensive area of interest and activities over the years and various useful techniques have been developed. They include: chemical devulcanization, ${ }^{25,26}$ thermal devulcanization, ${ }^{27,28}$ mechanical, ${ }^{29}$ chemomechanical, ${ }^{30-39}$ thermomechanical, ${ }^{40}$ thermochemical, ${ }^{41-48}$ ultrasonic, ${ }^{49-55}$ and some less effective methods, ${ }^{56,57}$ and microbial devulcanization. ${ }^{67-70}$ 
- Chemical devulcanization - The devulcanization is carried out by refluxing a mixture of rubber peelings and an aromatic solvent with an aqueous alkaline solution of the catalyst. The mixture is then stirred vigorously for 2 hours at reflux temperature below $100^{\circ} \mathrm{C}$ and then the rubber is filtered off, washed and dried. ${ }^{25}$ There is also a chemical regeneration process where chemicals are added to the rubber and stirred with very little shear. ${ }^{26}$ A different process treats the scrap with ferrous chloride and phenylhydrazine for several hours at normal room temperature and pressure. $^{27}$

- Thermal devulcanization - This process heats the rubber crumb at a high enough temperature without chemicals and is only applicable to NR. The microwave energy causes molecular motion and this raises the temperature of the scrap rubber, causing crosslinks to be broken. ${ }^{28}$ It is possible to avoid damage to the carbon-carbon and break the sulfur-sulfur and carbon-sulfur bonds if the microwave energy can be controlled.

- Mechanical - The crosslink density of solvent swollen chloroprene and EPDM slurries were catalytically reduced using screens, composed of alloys of iron and copper. ${ }^{29}$ This process achieved a 43\% devulcanization. The tensile properties and flex life deteriorated when 5 and 10 parts of the polychloroprene in a polychloroprene compound were replaced with the regenerated material. The compound containing the regenerated material had viscosities and shorter scorch safety than the virgin rubber.

- Chemomechanical - The method mixes chemicals with scrap rubber often on two-roll mills and internal mixers to achieve devulcanization. Scrap rubber crumb from vulcanized tire compound was masticated on a two-roll mill with sulfur, diphenylguanidine and zinc oxide. ${ }^{30}$ In a separate process, ground rubber crumb was mixed with peptizers and some rubber chemicals to regenerate the rubber. This increased the plasticity of the crumb and made it easier to mix with virgin material to reduce cost. ${ }^{31}$ Other processes use accelerators, activators and curatives, as a master batch, which helps the material to be reused without further processing. ${ }^{32-35}$ The use of natural occurring material to regenerate rubber crumb has also been investigated. One agent was a diallyl disulfide and the other was a natural occurring material that had a disulfide as the major component. The reclaiming agents broke into radicals, increasing as the temperature increased, because of shear. These radicals then combined with the polymer main chains radicals, 
preventing their recombining, hence the sol fraction increased. ${ }^{36-37}$ A process for reclaiming rubber crumb using standard equipment at a relatively low temperature was reported. ${ }^{38}$ The use of disulfides and standard equipment such as mill and extruder that applied shear to the rubber crumb caused it to regenerate. ${ }^{39}$

- Thermomechanical - A shear flow stage reactor that was basically a single screw extruder with a specially designed screw was used to devulcanized EDPM scrap thermomechanically. The temperatures reached 250 to $300^{\circ} \mathrm{C}$ by the shearing of the rubber crumbs. This was an efficient method of generating heat in the rubber by shearing it. No external source of heat was required in this case. ${ }^{40}$

- Thermochemical - This process reclaim scrap rubber without using normal alkali or acid. The process was performed in a steam or dry autoclaves at temperatures in the range of $150-190^{\circ} \mathrm{C}$ for a given period of time after which the material was removed and flattened on a two roll mill. A wide variety of organic chemicals were used to carry out this process. ${ }^{41}$ The use of organic long chain saturated acids and long chain aliphatic amines to reclaim rubber has been reported. ${ }^{42}$ Other chemicals such as bis(trialkyl phenol) sulfides, ${ }^{43}$ phenol sulfoxide, ${ }^{44}$ dialkyl aryl methyl hydroperoxides, ${ }^{45}$ and aromatic amine sulfides ${ }^{46,47}$ have also been used to reclaim rubber. A process of regeneration by blending the ground scrap with a plasticizing mixture of dipentene, 4 parts tall oil, 2 parts of a highly aromatic tar distillate and catalyst such as phenylhydrazine - zinc chloride complex, then placing it in a kettle at 150 to $190^{\circ} \mathrm{C}$ leaving about $8 \%$ undisolved has also been successful in reclaiming scrap rubber. ${ }^{48}$

- Ultrasonic devulcanization - Ultrasonic waves can be used to generate sufficient level effects that would be suitable to initiate the breaking down of the sulfur crosslinks. Since the sulfursulfur bonds have lower bond energies than those of the carbon-carbon bonds in the polymer backbone, the ultrasonic waves should have enough energy to cause devulcanization. The process does not require solvent or plasticizer and the resulting material can be revulcanized. ${ }^{49}$ The early work of Isayev et $a l^{50}$ on the development of ultrasonic technology for devulcanization of waste rubbers showed that the ultrasonic waves of certain levels in the presence of pressure and heat rapidly break up the three dimensional network in crosslink rubbers. The devulcanized rubber was reprocessed, shaped and revulcanized in much the same 
way as a virgin rubber. The work was carried out with model styrene-butadiene rubber (SBR) and with ground rubber tire (GRT). Curing behavior, rheological properties, and structural characteristics of rubbers devulcanized at various processing conditions were studies, as well as mechanical properties of revulcanized rubber samples. The process led to a breakdown of the carbon-carbon bonds in the molecular chains. The subsequent efforts were directed to improve the selectivity of the ultrasonic devulcanization process in breaking down the chemical crosslinks so that less degradation of the rubber occurred. Later work on the use of ultrasonic waves to recycle scrap rubber was also very successful. The effect of ultrasonic treatment on crosslink density, gel/sol ratio and glass transition temperature of a styrene-butadiene rubber (SBR) vulcanizate showed large reduction in the crosslink density and the gel formation. ${ }^{51}$ The mechanical properties of the revulcanized SBR were measured and showed that under some processing conditions, the tensile strength of the revulcanized SBR was much higher than the original vulcanizates with no change in elongation..$^{52}$ In the case of NR, the degree of devulcanization passed through a maximum at an intermediate level of ultrasonic energy and the mechanical properties depended upon the revulcanization recipe. ${ }^{53}$ Other studies showed that an increasing carbon black level resulted in an increase in the degree of devulcanization. The ultrasonic treatment appeared to cause a partial deactivation of carbon black. ${ }^{54}$ Continuous ultrasonic devulcanization of carbon black filled synthetic polyisoprene (IR) and natural rubber showed a greater extent of devulcanization than CB filled NR. This difference was attributed to the amount of stereoregular structures in the IR and NR rubbers. ${ }^{55}$

Other methods have also been used to devulcanize scrap EPDM rubber crumb. For example, Tzoganakis et al. ${ }^{56}$ used supercrititical $\mathrm{CO}_{2}$ in an industrial-scale twin screw extruder to devulcanize scrap EPDM crumb. At the same time, effect of processing conditions such as screw speed and feed rate on the sol and gel fractions, degree of devulcanization and Mooney viscosity of devulcanized rubber were also investigated. Ground rubber tire (GRT) has been used as a dispersed phase in a thermoplastic matrix with the use of compatibilizers. The properties achieved were inferior and thus GRT based thermoplastic elastomers (TPE) had limited applications. $^{57}$

All the evidence seems to suggest that there are a large number of advanced thermal, mechanical, chemical, and radiation processes available for reclaiming rubber waste. They 
include thermal process, heater or pan process, digester process, ambient grinding, cryogenic grinding, wet grinding, chemomechanical, thermomechanical, thermochemical, ultrasonic and microwaves. Numerous techniques for recycling rubber waste have also been developed. They are autoclave, microwaves heater, ultrasonic reactor, twin screw extruder, and internal batch mixer. The analytical methods for testing and characterizing devulcanized rubber waste are: solvent swelling, thermogravimetry analysis (TGA), solid-State H neutron mass spectroscopy (NMR), differential scanning calorimeter (DSC), atomic absorption spectroscopy, inductively coupled plasma atomic emission spectroscopy (ICP-AES), inductively coupled plasma optical emission spectroscopy (ICP-OES) and elemental analysis which involves the determination of the mass fraction of carbon, hydrogen, nitrogen, and heteroatoms (X) (CNHX).

\section{Chemical and microbial devulcanization of rubber waste}

EPDM has different reactivity towards devulcanization compared with natural rubber (NR) vulcanizate when treated with aromatic disulfides because of the difference in the rubber chain structure and the crosslink sites. ${ }^{6}$ In the period 1995-2005, a group at the University of Twente spent a huge amount of effort to devulcanize and reuse scrap EPDM rubber. Two papers were of significant interest to the authors. One reported modeling on the kinetics of an EPDM devulcanization in an internal batch mixer using hexadecylamine (HAD) as the devulcanizing agent. $^{58}$ The model included all the rate determining parameters that occur during the devulcanization process such as temperature, shear rate, reactant concentrations and times. HAD was optimally used for the main reaction with the crosslinks and performed well in the devulcanization process. Effect of disulfides as devulcanizers on the thermochemical recycling of NR and EPDM vulcanizates was also studied. It was interesting that NR sulfur vulcanizates were completely plasticized when heated with diphenyldisulfide at $200^{\circ} \mathrm{C}$. It was concluded that both main chain scission and crosslink scission caused the network breakdown. For EPDM a temperature range of $200-275^{\circ} \mathrm{C}$ was used, and it was found that there was almost no devulcanization of EPDM sulfur vulcanizates at $200^{\circ} \mathrm{C}$ in the presence of diphenyldisulfide. However at 225 and $250^{\circ} \mathrm{C}$, there was only slightly more devulcanization. ${ }^{59}$

Fig. 3 shows a devulcanization reaction mechanism proposed by Mouri et al. ${ }^{60}$. These workers studied mechanism of devulcanization by shear flow stage reaction control technology for sulfur vulcanized EPDM rubber based on the network structure of the devulcanized rubber 
and behavior of crosslinking bond breakage. They found that the sulfur crosslinks of the vulcanized rubber broke selectively during the devulcanization reaction. There were three types of crosslinks, monosulfide, disulfide and polysulfide. At the initial stage of the reaction, polysulfide and disulfide crosslinks changed into monosulfide ones by heat. Furthermore, monosulfide crosslinks were broken by the addition of shear stress and finally, a devulcanized rubber was obtained. Residual sulfur atoms at the broken crosslinking bonds were stabilized by the reaction of adjacent hydrogen atoms, and changed into less reactive sulfur functional groups.

Fukumori et al. ${ }^{61}$ proposed another perspective for devulcanization. The basic understanding of the cleavage of crosslinks under high shear stress which was suggested by these workers is as follows. As shown in Fig. 4, there appears to be only a small difference in the energy between C-C bonds, C-S and S-S bonds. The energies of C-C, C-S and S-S bonds were 370, 310, and $270 \mathrm{~kJ} / \mathrm{mol}$, respectively. It is worth mentioning that for C-C, C-S and S-S bonds energies 345, 270, and $240 \mathrm{~kJ} / \mathrm{mol}$ have been reported, ${ }^{5}$ which are somewhat different from the ones reported by Fukumori.

By simple heating in a pressure vessel, cleavage of both C-C, C-S and S-S bonds may occur unselectively. Hence, this leads to the lowering of the mechanical properties of the reclaimed rubber by the conventional method. On the other hand, with regard to the elastic constant $k$ for these bonds (estimated approximately on the basis of the values for crystals), the k-value for the S-S bonds can be estimated to be about 1/30th of that of the C-C bonds, as shown in Fig. 4(a). Generally, it is understood that the mechanical behavior of crosslinked rubber may be mainly controlled by the entropic term in the strain energy. In contrast with this entropic deformation behavior, at extremely high shear stresses induced by filling and kneading in the reactor, most of the rubber molecules may become fully elongated to their limited extensibility. Under these conditions, the S-S bonds having lower elastic constant may become more extended in comparison with the C-C bonds, having higher elastic constant in an elastic manner as shown in Fig. 4(b). That is to say, the elastic energy induced by high shearing may be particularly effective on the S-S bonds, causing the selective breakage of the crosslink points.

Cavalieri et al. ${ }^{62}$ and Magini et al. ${ }^{63}$ proposed a different mechanism for the devulcanization of waste rubber. They suggested that devulcanization could be carried out with the aid of both shearing forces and chemical agents. A phenolic antioxidant [2,6-di-tert-butyl-4-methyl-phenol (BHT)] was used as reclaiming agent to prevent aging and capture mechanically generated 
macro-radicals (Fig. 5). When waste rubber powder underwent mechanical shearing, most of the reclaiming agent, 2-mercaptobenzothiazole disulfide (MBTS), transformed into radicals due to the temperature rising and also mechanical shearing. These radicals then combined with the broken polymer radicals and prevented the recombination of the polymer radicals as shown in Fig. $6 .{ }^{64}$ In other investigations, ${ }^{65,66}$ diphenyl disulfide (DD) as reclaiming agent was dissolved in $\mathrm{scCO}_{2}$ (supercritical $\mathrm{CO}_{2}$ ) and the DD molecules solvated by the $\mathrm{scO}_{2}$ penetration into the rubber vulcanizate. The presence of DD in the rubber vulcanizate led to the crosslink cleavage as shown in Fig. 7.

In terms of environmental conservation, biological processes (microbial metabolism) are

useful for devulcanization. ${ }^{67,68}$ Some microbes exhibit biological activity toward sulfur and break down the sulfur crosslinks in rubber by oxidizing sulfur to sulfate. For example, waste rubber products are devulcanized by various Thiobacillus species. However, this method is slow, time consuming and has low conversion efficiency. Other miscellaneous methods such as devulcanization in supercritical carbon dioxide are also available but are not yet of industrial importance. $^{69}$

Reportedly, Guangming et al. ${ }^{70}$ succeeded to devulcanize waste rubber by T. ferrooxidants microbe (Fig. 8). The first step of the microbial desulfurization was the detoxification of the waste rubber powder to remove additives which inhibited microbial growth. Then the waste rubber powder was mixed with the sulfur-utilizing microorganisms, which produced the sulfuroxidizing activity of enzymes to remove the sulfur links. The study showed that the crosslinks of the devulcanized rubber were ruptured at a certain depth. Ion chromatography (IC), Fouriertransform infrared spectroscopy (FT-IR), and X-ray photoelectron spectroscopy (XPS) techniques were used to determine which microorganism was most bio-reactive. This was done by monitoring the level of sulfate in solution, detect some groups, and characterize the oxidation state of sulfur in solids, respectively. ${ }^{71}$

\section{Kinetics of chemical vulcanization of rubber and chemical devulcanization of scrap rubber}

Vulcanization is a chemical reaction and is characterized by using kinetic parameters. Due to the complex reactions taking place during vulcanization, phenomenological models usually are used 
for kinetic study. These models are simple to compute and are based on the rate of reaction as it is shown in equation $1 .^{72}$

$$
\frac{d c}{d t}=k(T) f(c)
$$

where $\mathrm{c}$ is the degree or extent of vulcanization, $\mathrm{k}$ is the rate constant as a function of temperature, and $f(c)$ is a function of the degree of vulcanization. The degree of vulcanization can be measured by tracking the concentration of reactants and products but this process is difficult to monitor and also involves costly spectroscopic analysis. However, as the vulcanization reaction is exothermic in nature, it can be assumed that the heat released during the reaction is proportional to the degree of vulcanization.

Flynn-Wall and Ozawa (FWO) integral isoconversional method is used for calculating activation energy of a devulcanization reaction, using thermogravimetry analysis (TGA) according to equation (2). ${ }^{73-76}$

$$
\operatorname{Ln} \beta=\ln \frac{A E}{g(\alpha) R}-5.330-1.052 \frac{E}{R T}
$$

where $\beta$ is the heating rate, $\mathrm{A}$ is the pre-exponential factor, $\alpha$ is the conversion at temperature $\mathrm{T}$, $\mathrm{E}$ is the activation energy, and $\mathrm{R}$ is the gas constant. The FWO method is based on the Doyle ${ }^{77}$ approximation and assumes that the reaction rate, at a specified conversion, is only a function of the temperature. For different heating rates at a constant conversion, a linear relationship is observed by plotting $\log \beta$ versus $1 / \mathrm{T}$, and $\mathrm{E}$ is obtained from the angular coefficient of the straight line. ${ }^{78,79}$

\section{Kinetics of chemical revulcanization of devulcanized scrap rubber}

Isayev and Sujan ${ }^{80}$ devulcanized ground rubber tire (GRT) using a coaxial ultrasonic devulcanization reactor at different ultrasonic amplitudes. The devulcanized samples were revulcanized isothermally using a sulfur-based recipe at various temperatures using an advanced polymer analyzer (APA 2000). The curves generated showed a reversion in the cure that was more obvious at higher temperatures. A simple vulcanization model was used to fit these cure curves and the corresponding kinetic model parameters were determined. Devulcanized samples 
were cured nonisothermally in the APA at various constant heating rates and multiple heating steps to predict nonisothermal curing behavior, which included reversion. The crosslink density and gel fraction of the samples cured in the APA were determined and correlated to the state of cure at different times during the curing reaction. Utilizing this information along with the cure kinetics, the crosslink density distribution of compression-molded disks were predicted and compared to experimental data. They subsequently derived an isothermal and a non-isothermal model for predicting the kinetic parameters for revulcanizing devulcanized GRT. For the isothermal case, they used equation 3 to calculate the state of re-cure $(\alpha)$.

$$
\frac{d \alpha}{d t}=n k^{1 / n} \alpha^{(n-1) / n}(1-\alpha)^{(n+1) / n}
$$

where $\mathrm{t}$ is the curing time difference between the time and the induction time, $\mathrm{n}$ is the order of the reaction, $\alpha$ is the state of cure, and $\mathrm{k}$ is the rate constant with the Arrhenius type temperature dependence:

$$
k=k_{0} \exp \left(-\frac{E}{R T}\right)
$$

where $k_{0}$ is the pre exponential factor, $\mathrm{E}$ is the activation energy, and $\mathrm{R}$ is the Universal gas constant. The nonisothermal case was analyzed, assuming that nonisothermal conditions exposed by the sample consisted of many infinitesimal isothermal time steps, $\Delta t=t_{j}-t_{j-1}$. Using this assumption, the temperature profile was broken into small isothermal time steps and the nonisothermal induction time, $t_{I}$, was obtained from isothermal induction time, $t_{i}$, using the concept of induction time index :

$$
\bar{t}=\int_{0}^{t_{I}} \frac{d t}{t_{i}(T)}=1
$$

where isothermal induction time , $t_{i}(T)$, at each time step is given by equation (6).

$$
t_{i}(T)=t_{i 0} \exp \left(\frac{E_{t i}}{R T}\right)
$$

where $t_{i 0}$ and $E_{t i}$ are material constants independent of the cure temperature. When the value of the dimensionless induction time index, $\bar{t}$, reaches unity, the upper limit of the integration is taken as the nonisothermal induction time. The same assumption of infinitesimal isothermal time 
steps was used for the determination of the cumulative state of cure. The following equation was used for the determination of the cumulative state of cure: ${ }^{81}$

$$
\begin{aligned}
\alpha_{j}=\alpha_{j-1}+ & \left.\frac{k_{1}(T)}{k_{1}(T)+k_{2}(T)}\left\{1-\exp \left[-k_{1}(T)+k_{2}(T)\right)(\Delta t)\right]\right\} \\
& +\frac{k_{2}(T)}{k_{1}(T)+k_{2}(T)-k_{3}(T)} X\left\{\exp \left[-k_{3}(T)(\Delta t)\right]\right. \\
& \left.-\exp \left[-\left(k_{1}(T)+k_{2}(T)\right)(\Delta t)\right]\right\} \text { for } t \geq t_{i}
\end{aligned}
$$

where $\alpha_{j}$ is the state of cure at any given instant after the induction period. The main disadvantage of using the above method is that it is unable to describe the induction period of cure, and this method requires the induction time to be defined as an explicit kinetic parameter.

\section{Techniques for reclaiming EPDM rubber waste}

\subsection{Autoclave}

Ostad Movahed et al. ${ }^{82}$ used an industrial autoclave which provided both heating and high pressure steam for devulcanizing an automotive EPDM waste rubber powder. The powder was a mixture of several aged and new automotive rubber with an average particle size less than $1 \mathrm{~mm}$. To aid the devulcanization process, 2-mercaptobenzothiazoledisulfide (MBTS) and tetramethylthiuram disulfide (TMTD), and aromatic and aliphatic oils were also used. MBTS and TMTD were used as devulcanizing agents. The autoclave was $4.5 \mathrm{~m}$ long and $1.5 \mathrm{~m}$ in diameter and had a nominal capacity of 8000 litres. About $250 \mathrm{~kg}$ of the oil-soaked waste powder was placed in the autoclave and the door was shut tight. Devulcanization was carried out in steam at $165^{\circ} \mathrm{C}$ under 6 bar pressure, and at $175^{\circ} \mathrm{C}$ under 8 bar pressure, to produce devulcanized rubber compounds. It took $8 \mathrm{~h}$ to complete the process. The devulcanized waste powder, which looked spongy and rather inconsistent, was then removed from the autoclave and allowed to dry at ambient temperature for $24 \mathrm{~h}$ before it was processed on an industrial two roll mills for $2 \mathrm{~min}$ to produce a more consistent and homogenous compound for further use. Then a portion of the virgin EPDM rubber, which was used in a common formulation for the automotive rubber strips, was replaced with the devulcanized product to produce blends, which were revulcanized using a semi-efficient (SEV) vulcanization system. The viscosity, cure and mechanical properties of the blends were subsequently determined. The waste powder from the discarded EPDM automotive 
parts was successfully devulcanized using an industrial autoclave. The oils had different effects on the devulcanization of the waste powder and MBTS was a more efficient devulcanizing agent than TMTD. The devulcanization percentage was calculated according to the procedure described in ASTM D297-13, using methanol and a Pycnometer. The devulcanization percentages varied between 28.6 to $94.7 \%$ depending on the devulcanization conditions. Replacing a portion of the virgin EPDM rubber with up to $60 \mathrm{wt} \%$ of the devulcanized powder in the common formulation for the automotive rubber strips reduced the viscosity, which was beneficial to the processing of the rubber compound. Also, replacing a portion of the virgin rubber with $60 \mathrm{wt} \%$ of the devulcanized powder in the formulation had no adverse effect on the scorch and optimum cure times, crosslink density and rate of cure of the rubber compound. In addition, replacing $20 \mathrm{wt} \%$ of the virgin rubber with the devulcanized powder in the blend had no adverse effect on the hardness, compression set, and modulus at $20 \%$ elongation of the rubber vulcanizate. Therefore, it was concluded that the devulcanized powder could be used in low quantity in order not to deteriorate the mechanical properties of the virgin rubber too much. In addition, there was sufficient evidence from this study to suggest that the devulcanized waste powder could replace a portion of the virgin rubber in the automotive rubber strips. This provided potentially a new recycling route for the waste powder.

\subsection{Microwaves heating}

Microwaves are electromagnetic radiation with wavelengths from $1 \mathrm{~mm}$ to $1 \mathrm{~m}$, and corresponding frequencies between $300 \mathrm{MHz}$ and $300 \mathrm{GHz}{ }^{83}$ The two most commonly used frequencies are 0.915 and $2.45 \mathrm{GHz}$. Microwaves are used as a source of energy to break down crosslinks, mainly C-S and S-S linkages. This method has the advantage of volumetric heating, which is generated from the inner parts to the surface of the material and does not require an appreciable amount of time to affect temperature changes, and promotes efficient and uniform

heating throughout rubber. ${ }^{84}$ However, materials heated using microwaves need to have a certain polarity, which is an intrinsic characteristic of a material. It is known that the microwave absorption and dispersion properties of EPDM are poor. ${ }^{85}$ This issue may be resolved by adding polar fillers such as silica and carbon black to the rubber.

Ostad Movahed et al. ${ }^{64}$ studied the devulcanization of an automotive EPDM waste rubber powder by microwave heating and various devulcanizing chemical agents. The EPDM waste 
powder was a mixture of several aged and new automotive rubber components with an average particle size less than $1 \mathrm{~mm}$. Originally, the powder was made of particles roughly $1 \mathrm{~cm}$ in size but this was not suitable for devulcanization, because large particles did not devulcanize well. Therefore, the powder was ground to produce particles roughly $1 \mathrm{~mm}$ in size before devulcanization began. First $N$-cyclohexyl-2-benzothiazole sulfenamide (CBS), dipentamethylenethiuram tetrasulfide (DPTT), hexadecylamine (HAD), mercaptobenzothiazole (MBT), MBTS, and TMTD chemicals, which were used as devulcanizing agents, were mixed with the aromatic oil and then added to the waste powder in a $500 \mathrm{ml}$ glass beaker. Note that HAD was reported to be a good devulcanizer for EPDM rubber ${ }^{58}$ and hence it was used in this study. The waste powder was soaked in the oil for $24 \mathrm{~h}$ to allow it to penetrate into the rubber fully. Microwave oven had an output power of $900 \mathrm{~W}$, frequency of $2000 \mathrm{MHz}$, and internal capacity of 30 litres. Devulcanization was carried out at 200, 230 and $260^{\circ} \mathrm{C}$, for 3 minutes. Effect of different amounts of the aromatic and aliphatic oils on the devulcanization of the waste powder in the presence of a devulcanizing agent was also investigated. It was found that using microwave heating at these temperatures, and with the aid of CBS, HDA, and MBT chemicals and aromatic and aliphatic oils, the EPDM waste power was successfully devulcanized. The effectiveness of the chemicals to devulcanize the waste powder was summarized as: HDA > MBT $=$ CBS $>$ MBTS $=$ DPTT $>$ TMTD. The lowest devulcanization was measured for the compound containing TMTD at about 75 to $80 \%$ and the highest for the compound with HDA at about 91 to $94 \%$ as temperature was increased from 200 to $260^{\circ} \mathrm{C}$ (Fig. 9). The process was more efficient at higher temperatures. The devulcanized waste powder was then revulcanized with a sulfur cure system. The scorch and optimum cure times were very short, i.e. less than 1 min, and the rate of cure very slow, i.e. as low as $1.7 \mathrm{~S}^{-1}$. The revulcanized rubber compounds had low crosslink densities as indicated by the $\Delta$ torque values. $\Delta$ torque was the difference between the maximum and minimum torque values on the cure trace of the rubber compounds and was an indication of crosslink density changes in the rubber. The hardness, tensile strength, and elongation at break of the revulcanized compounds were in the range of 49-79 Shore A, 2.03.7 MPa, and 34-211\%, respectively. This indicated that these revulcanized compounds could never be used for heavy duty applications. The most interesting finding of the study was the fact that the cure and mechanical properties of the revulcanized compounds were dependent on the composition and devulcanization conditions of the waste powder. 
6.3. Twin screw extruders and internal mixers

Twin screw extruders and internal mixers have been used to perform continuous devulcanization of scrap EPDM waste. ${ }^{6,58,86}$ Sutanto et al. ${ }^{86}$ applied a kinetic model to EPDM devulcanization in an extrusion process. Parameters that were included in the model were crosslink density, devulcanizing agent concentration, time, shear rate, and temperature. The extruder was considered as a series of plug flow and stirred tank reactors. The residence time was calculated using solid flow or liquid flow model, depending on the degree of decrosslinking. The model accurately predicted the decrosslinking degree inside the temperature boundary defined by the applied experimental conditions. Outside this boundary, the effect of chemical degradation on the measured conversion became more significant. A number of interesting results were reported. The model predicted the conversion in the extruder quite well. The analysis on the devulvcanizate did not show any significant amount of degradation product. The molecular weight of the devulcanizate was around $40 \%$ lower than the molecular weight of the virgin material, indicating less than one scission per polymer chain of the sol fraction. The successful continuous devulcanization process modeling showed that the extruder operating conditions could resemble the operating conditions in the batch system to attain the same shear and residence time. As a result of Sutanto's work and the work of many other researchers, ${ }^{58,59}$ continuous EPDM devulcanization in multi-screw extruder operations are in industrial operation in the USA.

Ostad Movahed et al. ${ }^{87}$ devulcanized some automotive EPDM waste rubber power in a semi-industrial twin screw extruder, which provided shearing force and reactor, along with MBTS chemical as a devulcanizing agent. This was carried out at feed screw speeds of 6 and 8 rpm, main screw speeds of 180 and $220 \mathrm{rpm}$ at a constant temperature of $220^{\circ} \mathrm{C}$. The twin screw extruder had a capacity of 100-250 kg/h. The machine was equipped with a feeder with adjustable feed rate screw, cooling and heating systems as well as a main screw with rotating speed control. The devulcanized waste powder was recycled by mixing different amounts of the devulcanized powder with a commercial EPDM-based automotive rubber strips compound (referred to as reference compound) to produce 8 blends. The blends, reference compound and devulcanized powder were then cured with a semi-efficient (SEV) vulcanization system. The viscosity, cure and mechanical properties of the blends were measured and compared with those 
of the reference compound to assess effect of the increasing amount of the devulcanized powder in the blends on the aforementioned properties. It emerged that that this method was efficient and practical for devulcanizing the automotive EPDM waste rubber powder and achieved 92\% devulcanization. In addition, the devulcanized rubber was obtained continuously at the head of the reactor in the form of strand. The surface appearance of the devulcanized rubber depended strongly on the devulcanization condition namely, screw speed, temperature of the screw channel (devulcanization temperature), feeding rate and raw material composition. When the operating conditions were not optimal, the surface of the strand appeared rough. When the rubber properties were measured, it emerged that the Mooney viscosity remained unchanged when up to $40 \mathrm{wt} \%$ of the devulcanized waste powder was in the blends with the virgin EPDM rubber. However, the viscosity decreased very substantially when the loading of the devulcanized waste powder in the blends was raised to its optimum. Lower viscosity was very beneficial for the ease of processing. The $\Delta$ torque, which indicated crosslink density changes in the rubber, was unaffected with $20 \mathrm{wt} \%$ of the devulcanized waste powder in the blends. The elongation at break was unaffected with $10 \mathrm{wt} \%$, hardness with $50 \mathrm{wt} \%$, compression set with $20 \mathrm{wt} \%$, and tensile strength with $10 \mathrm{wt} \%$ of the devulcanized powder in the blends. The scorch and optimum cure times shortened and the cure rate index increased for the blends containing an increasing loading of the devulcanized powder. Interestingly, the cure characteristics and mechanical properties of the EPDM rubber vulcanizate were affected by the level of the devulcanized waste rubber.

\section{Methods for characterizing and testing of vulcanized rubber applied to revulcanized EPDM scrap rubber}

\subsection{Swelling test}

Swelling in solvents such as toluene is an effective and commonly used method for measuring crosslink density (CLD) and sol content of rubber vulcanizates. The crosslink density is calculated using the Flory-Rehner equation: ${ }^{8}$

$$
\rho_{c}=-\frac{1}{V_{s}} \frac{\ln \left(1-v_{r}^{0}\right)+v_{r}^{0}+x\left(v_{r}^{0}\right)^{2}}{\left(v_{r}^{0}\right)^{1 / 3}-v_{r}^{0} / 2}
$$


where $\rho_{c}$ is the $\operatorname{CLD}\left(\mathrm{mol} / \mathrm{m}^{3}\right), V_{s}$ is the molar volume of toluene $\left(1.069 \times 10^{-4} \mathrm{~m}^{3} / \mathrm{mol}\right.$ at $\left.25^{\circ} \mathrm{C}\right)$, $v_{r}^{0}$ is the volume fraction of rubber (polymer) in the swollen gel, and $\chi$ is the interaction parameter, which was calculated using the following equations: ${ }^{89,90}$

$$
\begin{aligned}
& \chi=0.429+0.218 v_{r}^{o} \\
& v_{r}^{o}=\frac{1}{1+\frac{d_{r}}{d_{s}}\left(\frac{1-f_{s o l}}{1-f_{s o l}-f_{f i l}}\right)\left(\frac{w_{s}}{w_{0}}-1\right)}
\end{aligned}
$$

where $d_{r}$ and $d_{s}$ are the densities of the rubber and solvent, respectively; $f_{\text {sol }}$ is the weight fraction of soluble material in the initial sample (sol fraction); $f_{f i l}$ is the initial weight fraction of filler in the sample; $w_{s}$ is the weight of the swollen gel; and $w_{0}$ is the weight of the dried sample.

The sol content and devulcanization \% were calculated as follows:

$$
\text { Sol content }=f_{\text {sol }} X 100=\frac{w_{i}-w_{0}}{w_{i}} \times 100
$$

Devulcanization $(\%)=100 \times($ initial waste rubber CLD - final rubber CLD)/initial waste rubber CLD

where $w_{i}$ is the initial weight of the sample.

Equations 8-12 have been used to measure CLD and sol content of some revulcanized EPDM waste rubbers in toluene. For example, Bani et al. ${ }^{91}$ used the Flory-Rehner equation, as derived from rubber elasticity theory, to calculate the CLD of some revulcanized carbon blackfilled devulcanized/virgin EPDM rubber. They reported values around $49-57 \mathrm{~mol} / \mathrm{m}^{3}$ for their samples, depending on the type of sulfur links in the rubber. The author and co-workers ${ }^{64}$ calculated the CLD and sol content of EPDM waste powder after oil extraction by acetone using equations (8) and (11), respectively, and reported a value $186 \mathrm{~mol} / \mathrm{m}^{3}$ for the CLD and $0.5 \%$ for the sol content. After the waste powder was devulcanized under different conditions, the CLD and sol content were somewhere between 10 and $51 \mathrm{~mol} / \mathrm{m}^{3}$ and 2.8 and $13.6 \%$, respectively. Clearly the equations used to calculate CLD and sol content for vulcanized rubbers are perfectly applicable to devulcanized scrap rubber and revulcanized blends of devulcanized/virgin rubber. 


\subsection{Chain scission in a polymer network.}

One major work carried out by Horikx ${ }^{92}$ has been instrumental in our understanding of the devulcanization process of rubber waste. This worker investigated relations between the soluble fraction and the number of effective chains between crosslinks in a three-dimensional network undergoing a scission reaction. This lead to a correlation between the weight loss in a degraded NR network as a function of the percentage of the inactive chain. Three limiting cases were considered. They were random scission in the chains, scission in the chains directed by the crosslinks, and scission of the crosslinks only. The number of scissions was computed from the fraction of soluble material in a degraded network, as determined experimentally. This procedure was then applied to the oxidation of a NR vulcanizate. It emerged that in a NR sulfur-Santocure vulcanizate, the scission reaction accompanying the oxygen absorption at $100^{\circ} \mathrm{C}$, did not involve opening of the crosslinks but it could not be establish whether the scission in the chains was directed or at random. The study showed that there exited a simple relation between the soluble fraction of a network that had undergone scission and the effective number of chains in the gel fraction as determined by the swelling measurements. Furthermore, the fraction of soluble material in the degraded network was a measure of the number of scission.

\subsection{Thermogravimetry analysis (TGA) in determining the waste rubber composition}

TGA was used as described in ASTMD6370-99 and E1131-08 methods to quantity carbon black and ash (filler) in waste rubber and nonorganic solids in liquids and solids. Ostad Movahed et al. ${ }^{64,82,87}$ analyzed an automotive EPDM waste rubber powder by TGA (Fig. 10). The TGA results showed that EPDM degradation began at $287.6^{\circ} \mathrm{C}$ and finished at $547.8^{\circ} \mathrm{C}$. Mass loss was also observed in the range $26.2-287.6^{\circ} \mathrm{C}$, because of the presence of the oil. In addition to the mass loss related to the oil and rubber, a transition in the range $550-613^{\circ} \mathrm{C}$ was observed. This was attributed to the combustion of carbon black present in the sample (after changing the atmosphere to air at $550^{\circ} \mathrm{C}$ ). On the TGA curve, there was a clear peak around $700^{\circ} \mathrm{C}$, probably related to the content of calcium carbonate. The waste powder was a mixture from several rubber articles, which contained carbon black and calcium carbonate. The calcium carbonate exhibited decomposition to calcium oxide with a weight loss in the region of $700^{\circ} \mathrm{C}$ (Fig. 10). The unburned residue was attributed to minerals and metals in the sample. Only $38.88 \mathrm{wt} \%$ of this 
waste rubber or exactly $32.1 \mathrm{wt} \%$ of the initial waste rubber (before acetone extraction), was EPDM rubber.

\subsection{Solid-State H neutron mass spectroscopy}

Neutron mass spectroscopy (NMR) is a powerful technique to investigate the chemical structure of insoluble materials. For EPDM rubber, NMR can be used to quantify the ethylene to propylene ( $\mathrm{E} / \mathrm{P})$ weight ratio and has been proposed as a means to investigate crosslink density through the relative intensity of the diene peak, the relative width of the ethylene peak, ${ }^{94}$ and the measurement of the spin-spin $T_{2}$ relaxation time. ${ }^{95-100}$ As an illustration, Moldovan et al..$^{99}$ studied the dynamic heterogeneities of polymer chains for a series of EPDM rubbers with carbon black N683 filler content varying from 20 to 70 parts per hundred rubber by weight (phr). Proton Hahn-echo decays were measured with an acquisition delay that played the role of a dipolar filter and removed the signal contribution from the bound polymer chains. The Hahn-echo decay was considered which was weighted only by the fluctuating part of the polymer chains. In addition, an exponential correlation function was considered in the derivation of the functional form for the Hahn-echo decay. The power-law correlation function was found to be inadequate to describe the Hahn-echo decay of mobile EPDM rubber segments for carbon black-filled samples in the investigated time domain. Liang et al. ${ }^{93}$ suggested that NMR and Fourier transform infrared spectroscopy (FTIR) were not suitable for the analysis of the waste rubber samples due to the line-broadening effect of paramagnetic species present in large concentrations (Fig. 11).

\subsection{Differential scanning calorimeter (DSC)}

Differential scanning calorimeter (DSC) presents qualitative information on crosslink density and relative amount of ethylene in the EPDM rubber through measuring glass transition $\left(\mathrm{T}_{\mathrm{g}}\right)$ and melting temperature $\left(\mathrm{T}_{\mathrm{m}}\right)$ of the compound and is a complementary technique to TGA. ${ }^{101}$ Liang et al. ${ }^{93}$ used several EPDM waste ground rubber (WGR) grades and thermo mechanically regenerated and studied them with DSC (Fig. 12). As shown in Fig. 12, near $40^{\circ} \mathrm{C}$, a change in heat capacity corresponding to the glass transition is observed. For all the WGR grades, this transition is followed by an endothermic peak that is attributed to the melting point of ethylene crystals when high enough concentration (typically above $50 \mathrm{w} / \mathrm{w} \%$ ) of ethylene was present. 
7.6. Atomic absorption spectroscopy, ICP-OES, and CHNS analysis

Atomic absorption spectroscopy, inductively coupled plasma atomic emission spectroscopy (ICP-AES), and inductively coupled plasma optical emission spectrometry (ICP-OES), are analytical techniques used for the detection of trace metals. ICP-OES, and elemental analysis which involves the determination of the mass fraction of carbon, hydrogen, nitrogen, and heteroatoms (X) (CNHX) like halogens and sulfur, are frequently used for determining the chemical composition of EPDM rubber waste. In an effort, Liang et al. ${ }^{93}$ used the aforementioned technique for various grades of WGR. They found that the total amount of $\mathrm{CaCO}_{3}, \mathrm{ZnO}, \mathrm{SiO}_{2}$ and $\mathrm{Al}_{2} \mathrm{O}_{3}$ ranged from 16.0 to $19.9 \%$ and the values of sulfur ranged from 0.1 to $0.4 \%$. In addition, two most important metals as impurities in WGR samples were calcium and zinc. Calcium weight ranged from 4.00 to $6.15 \%$. Calcium is often added as filler in the form of $\mathrm{CaCO}$, or it can be used as a processing aid in the form of calcium fatty acid salts. The use of $\mathrm{CaO}$ as a cure activator in concentrations ranging from 2 to $8 \%$ has also been reported. ${ }^{101}$ Zinc percentages were smaller, varying from 1.43 to $1.73 \%$. Its most probable source is $\mathrm{ZnO}$, which is used as activator. The other elements measured (cadmium, chromium, copper, iron, magnesium, manganese, sodium, nickel, phosphorous, and titanium) could not be detected above detection limit of the method $(0.01 \%)$ except for aluminum.

\section{Some aspects of the recycling and analytical testing of devulcanized EPDM rubber waste}

The ultimate target for recycling waste rubber is to replace virgin EPDM rubber entirely with devulcanized waste rubber. Bani et al. ${ }^{91}$ devulcanized an EPDM formulated rubber with the aid of microwave and replaced a part of virgin rubber with the devulcanized rubber. They concluded that the virgin rubber and devulcanized rubber had good interfacial adhesion, which helped to produce better products than those made of similar materials where the recycled part was made of ground undevulcanized EPDM rubber. Niloofar Kalantar et al. ${ }^{102}$ reviewed the use of waste polymer in asphalt to improve the properties of pavement. Nabil et al. ${ }^{103-109}$ studied properties of devulcanized EPDM rubber and virgin NR blends. They measured morphology, cure and mechanical properties of the blends and concluded that the blends could replace virgin NR in corresponding applications. The use of recycled EPDM in polypropylene (PP) as a thermoplastic elastomer was studied. ${ }^{110}$ The results indicated that good dispersion and compatibility between PP and recycled EPDM was obtained and incorporation of recycled- 
EPDM led to significant improvement in the PP impact strength. Effect of recycled-EPDM rubber on the mica-filled EPDM rubber compounds was measured. ${ }^{111}$ It was found that the scorch time decreased with increasing the recycled-EPDM content, whereas curing time and $\Delta$ torque showed the opposite trend. Wang et al. ${ }^{112}$ suggested an ingenious, simple, non-toxic, low energy consumption, labor unintensive process, which was carried out at ambient temperature and under pressure for reclaiming EPDM rubber. The reclaimed rubber was of a high quality and could be applied to waterproofing membranes. Pistor et al. ${ }^{113}$ studied effect of devulcanized EPDM rubber with microwave on the mechanical properties of correspondent blends with low density polyethylene (LDPE). They concluded that incorporation of the devulcanized EPDM rubber reduced toughness and increased elasticity modulus and impact resistance of the blends.

Santos et al. ${ }^{114}$ used 1-dodecanethiol chemical as a compatibilizer in the blend of virgin EPDM and recycled EPDM rubbers. They claimed that when using this chemical, more recycled EPDM rubber waste could be used without having a detrimental effect on the mechanical properties of the blend. For example, they used 1 unit of the recycled EPDM rubber waste with 1 unit of the virgin EPDM to produce a blend with a tensile strength of $10 \mathrm{MPa}$. When the formulation was altered to 1.5 unit of the recycled EPDM rubber waste with 1 unit of the virgin EPDM and 1 unit of 1-dodecanethiol, the tensile strength remained unchanged. Use of devulcanized EPDM rubber waste in a polypropylene (PP)/high density polyethylene (HDPE)/EPDM ternary blend was also investigated. ${ }^{115}$ In this study, ternary blends of the aforementioned polymers were prepared in a laboratory twin screw extruder with the level of the devulcanized EPDM rubber waste increasing from around 20 and 40 to $60 \mathrm{wt} \%$ at $20 \mathrm{wt} \%$ concentration of HDPE. The blends were subsequently cured with sulfur dynamic vulcanization method. Mechanical properties of the blends were measured and then compared with those of the virgin EPDM rubber. It was concluded that the properties of the blends after the devulcanized EPDM rubber waste was incorporated were comparable to those of the virgin EPDM rubber.

A more recent study by Isayev investigated the ultrasonic treatment of unfilled EPDM and silica-, nanoclay- and CB-filled EPDM mixtures using a coaxial ultrasonic extruder at various ultrasonic amplitudes. ${ }^{116}$ It was found that the storage and loss moduli and complex dynamic viscosity of untreated and ultrasonically treated silica-filled EPDM mixtures were significantly 
higher than those of the nanoclay- and CB-filled EPDM mixtures with the Tan Delta being significantly lower than that of the nanoclay-filled EPDM mixtures. The results further confirmed the versatile nature of the ultrasonic devulcanization technique when applied to different compounds. Ultrasonic devulcanization of tire rubber particles of 10 and 30 meshes using a new ultrasonic twin-extruder was carried out. ${ }^{117}$ The ultrasonic amplitude and devulcanization temperature were varied at a fixed frequency and the degree of devulcanization was investigated by measuring the crosslink density, gel fraction, and revulcanization behavior. Rubber of 30 mesh exhibited a lower die pressure and higher degree of devulcanization than that of rubber of 10 mesh. Revulcanizates with a greater degree of devulcanization exhibited a higher elongation at break, whereas those with a lower degree of devulcanization exhibited higher strength and modulus. Revulcanizates of rubber of 30 mesh exhibited a consistently higher elongation at break.

Mechanical methods for recycling scrap rubber also have proved to be effective. For example, EPDM rubber crumbs from used tyres were treated in batch and continuous processes to produce regenerated material. The effect of EPDM particle size, oil type and concentration as well as processing time, temperature, and mixing intensity were controlled for treatment in an internal batch mixer and a twin-screw extruder. The crosslink density reduced without the addition of a chemical agent. ${ }^{118}$ A study into the effect of EPDM particles size on its thermomechanical regeneration process in a batch mixer showed the recycled material decomposing into particle groups from 125 to $1000 \mu \mathrm{m}$ in size. There was also a significant crosslink reduction at the end of the process. ${ }^{119}$ EPDM rubber with varying crosslink densities and carbon black content as well as commercial EPDM waste ground rubber (WGR) were characterized using thermal and thermogravimetric (TGA) analysis. TGA was used to determine the amount of carbon black and inorganic material in the rubber and showed crosslink losses during heating. ${ }^{120}$ Processability, curing characteristics and vulcanizate properties of EPDM compounds containing ground waste EPDM (W-EPDM) were studied. ${ }^{121}$ The ground waste had particle sizes in the range of 2 to $50 \mu \mathrm{m}$, with an average size of $10 \mu \mathrm{m}$. Mooney scorch time and the maximum rheometric torque of the EPDM compound decreased gradually and the processability improved on addition of W-EPDM. Furthermore, the vulcanizate properties of the W-EPDM-filled EPDM compounds showed the reinforcing nature of the ultrafine W-EPDM particles. When W-EPDM was compared with the inert precipitated $\mathrm{CaCO}_{3}$ filler in an $\mathrm{EPDM}$ compound, the result showed 
that W-EPDM could be used as a cheap filler in EPDM compounds. W-EPDM could be incorporated into the window seal compound formulation and the drop in properties even at 100 phr of W-EPDM was within acceptable limit, hence providing a new route for recycling the scrap rubber.

Recently, Marvin et al. ${ }^{122}$ reviewed the latest development in rubber recycling including chemistry, processing and applications. They concluded that the future of rubber recycling is predetermined by two major developments. On one hand the depletion of natural resources such as crude oil in the case of rubber, and on the other hand the obligation to reuse as much material as possible. The traditional methods of rubber recycling for example grinding and reclaiming will maintain their value but the market for these products is limited, hence the quality of recycled rubber products must improve. The most serious adverse effect of the existing reclaiming processes is their influence on the polymer structure where the functionality of the material is not kept intact. Therefore, the future technology for recycling of scrap rubber must focus on decrosslinking with minimum effect on the polymer and hence on the functionality of the material. This means that catalysts and devulcanization aids must be chosen carefully to avoid damage to the polymer. In addition, compounding principles for blends of virgin with devulcanized rubber need to be developed. One problem is the presence of curing additives in the recycling material, which are still active. Thus the curing system and conditions for a blend of virgin and devulcanized rubber must be adjusted to build a network with properties as close to the properties of the original material as possible. These authors suggested that rubber products should be designed for recycling. Rubber should be looked at as a composite material for easy separation of the different components. The polymer network needs to be stable under normal service conditions might be triggered by external parameters to dissolve for recycling purposes. The study concluded that new sophisticated rubber recycling technologies have a promising future because they are solutions to the most urgent problems of depleting raw materials and increasing amounts of waste. Tire was identified to be the largest application area for recycling and only higher quality devulcanized rubber should be used in large quantities for high-level products.

9. Summary 
There are very advanced thermal, mechanical, chemical, and radiation processes available for reclaiming rubber waste. They include thermal process, heater or pan process, and digester process, ${ }^{8-15}$ ambient grinding, ${ }^{16-17}$ cryogenic grinding, ${ }^{18}$ wet grinding, ${ }^{19-24}$ chemical devulcanization, ${ }^{25,26}$ thermal devulcanization, ${ }^{27,28}$ mechanical, ${ }^{29}$ chemomechanical, ${ }^{30-39}$ thermomechanical. ${ }^{40}$ thermochemical, ${ }^{41-48}$ ultrasonic devulcanization, ${ }^{49-55}$ and many other less efficient methods. ${ }^{56,57}$ Numerous techniques for recycling rubber waste have also been developed. They are autoclave, ${ }^{82}$ microwaves heater, ${ }^{83-85}$, ultrasonic reactor, ${ }^{49-55,80}$ twin screw extruder, ${ }^{86,87}$ and internal batch mixer. ${ }^{6,58,59}$ The analytical methods for testing and characterizing devulcanized rubber waste are: solvent swelling, ${ }^{88}$ thermogravimetry analysis (TGA), ${ }^{64,74,76,78}$ solid-State H neutron mass spectroscopy (NMR), ${ }^{93,95-100}$ differential scanning calorimeter (DSC), ${ }^{101}$ atomic absorption spectroscopy, ${ }^{93,101}$ inductively coupled plasma atomic emission spectroscopy (ICP-AES), ${ }^{93,101}$ inductively coupled plasma optical emission spectroscopy (ICPOES), ${ }^{93,101}$ and elemental analysis which involves the determination of the mass fraction of carbon, hydrogen, nitrogen, ${ }^{93,101}$ and heteroatoms $(\mathrm{X})(\mathrm{CNHX}) .^{93,101}$ In addition to these techniques and processes, and methods for characterizing and testing of vulcanized rubber which can also be applied to revulcanized scrap rubber, ${ }^{88-90}$ kinetics of chemical revulcanization of devulcanized scrap rubber can be measured too. ${ }^{80,81}$ Moreover, the modern analytical techniques mentioned above will be instrumental in characterizing recycled/devulcanized rubber waste for efficient reuse with virgin rubber in blends and subsequent revulcanization of the virgin/devulcanized rubbers for industrial applications. The author and co-workers ${ }^{64,82,87}$ utilized some of these techniques and procedures to successfully devulcanize some EPDM scrap rubber.

Extensive studies $^{91-122}$ have shown promising results for reusing devulcanized rubber waste, for example reclaimed EPDM rubber waste, with virgin EPDM and other polymers without causing detrimental effects on the mechanical properties of the final product. Therefore, reclaimed EPDM rubber waste can be mixed with virgin EPDM and thermoplastics to make products such as carpets, mats, and possibly window seals for automobiles, ${ }^{64,82,87}$ and as mentioned earlier, ${ }^{112}$ it can also be applied to waterproofing membranes. It is increasingly evident that in a near future rubber waste can be recycled on a much larger scale than currently is done, offering major benefits to health, safety, and also the environment. In their review paper, Marvin et al. ${ }^{122}$ stated that the most serious adverse effect of the existing reclaiming processes is their influence on the polymer structure where the functionality of the material is not kept intact. 
They concluded that the future technology for recycling of scrap rubber must focus on decrosslinking with minimum effect on the polymer and its functionality. Also, Horikx ${ }^{92}$ showed that scission to crosslinks and rubber chains can be differentiated in the devulcanization process. Therefore, there is scope to improve the current recycling processes and procedures to recover the rubber more efficiently.

\section{Conclusions}

We are likely to see major advances in the recycling of scrap rubber in the near future, using the processes and methods mentioned above. In addition, the modern analytical techniques referred to above will be instrumental in characterizing recycled/devulcanized rubber waste for efficient reuse with virgin rubber in virgin/revulcanized rubber blends for industrial applications. Though, the main concern will be to avoid scission to the polymer chains and increase efficiency of the sulfur crosslink scission. Previous studies ${ }^{92}$ have shown that these two processes can be differentiated during the devulcanization process of scrap rubber, and this will help to create a more promising route to the recycling of rubber waste. Further research will be needed to advance the current state of the art in rubber waste management and recycling with a view to extend the application of devulcanized rubber waste to produce more high quality products for industrial uses. 


\section{References}

1 V. V. Rajan, W. K. Dierkes, R. Joseph, and J. W. M. Noordermeer, Prog. Polym. Sci. 31, 811 (2006).

2 V. L. Shulman, Introduction to Tire Recycling. European Tire Recycling Association (ETRA), 2008.

${ }^{3}$ ASTM Spec. Tech. Publ. N184A Glossary of terms relating to rubber and rubber technology. American Society for Testing and Materials, 1987.

${ }^{4}$ P. Sutantu, Development of a continuous process for EPDM Devulcanization in an Extruder, Ph.D dissertation: University of Twente, Netherland; 2006.

${ }^{5}$ J. Olmsted, and G. M. Williams, Chemistry: The Molecular Science: Mosby; 1997.

${ }^{6}$ P. Sutanto, F. L. Laksmana, F. Picchioni, and L. P. B. M. Janssen, Chemical Eng. Sci. 61, 6442 (2006).

${ }^{7}$ K. A. J. Dijkhuis, I. Babu, J. S. Lopulissa, J. W. M. Noordermeer, and W. K. Dierkes, Rubber Chem. Technol. 81, 190 (2008).

${ }^{8}$ E. W. Owen, Rubber Chem. Technol. 17, 544 (1944).

${ }^{9}$ D. S. Le Beau, Rubber Chem. Technol. 21, 895 (1948).

${ }^{10}$ W. C. Cook, Rubber Chem. Technol. 21, 166 (1948).

11 D. S. Le Beau, Rubber Chem. Technol. 22, 560 (1949).

12 J. C. Amberlang and G. E. P. Smith Jr., Rubber Chem. Techmol. 28, 322 (1955).

13 J. M. Ball, “Introduction to Rubber Technology,” M. Morton, ed., van Nostrand Reinhold, 1959, ch. 7.

14 J. Paul, paper \#50 presented at a meeting of the Rubber Division, ACS, Oct. 4-7, 1977, Cleveland; abstract in Rubber Chem. Technol. 51, 384 (1978).

${ }^{15}$ A. Nourry Editor, “Reclaim Rubber Its Development, Applications, And Future,” MacLaren and Sons, London, 1962.

${ }^{16}$ R. Kohler and J. O’Neill, paper \#35 presented at a meeting of the Rubber Division, ACS, Oct. 17-20, 1995, Cleveland, abstract in Rubber Chem. Technol. 69, 146 (1996).

${ }^{17}$ T. C. P. Lee, W. Millns, (to Gould, Inc.) U.S. 4,049, 588 (Sept. 20, 1997).

${ }^{18}$ G. B. Mottershead “Commercial Opportunities in Cryogenic Tire Recycling,” Rubber Association of Canada Seminar, October 1998.

${ }^{19} \mathrm{~K}$. Khait, paper\#24 presented at a meeting of the Rubber Division, ACS, Apr. 19-22, 1994 Chicago; abstract in Rubber Chem. Technol.73, 734 (1994).

${ }^{20}$ K. Khait, Rubber World, 216(2), 38 (1997).

${ }^{21}$ K. Khait,”Solid-State Shear Pulverization,” Technomics, Lancaster, 2001.

${ }^{22}$ W. F. Watson, paper\#117, presented at a meeting of the Rubber Division, ACS, Sep. 21-24, 1999, Orlando; abstract in Rubber Chem. Technol. 73, 172 (2000).

${ }^{23}$ K. F. Kelly and V. G. Nikolski, V. N. Balyberdine, N. Benham, I. Morris, B. M. Kelly, paper\#98 presented at a meeting of the Rubber Division, ACS, Oct. 21-24, 1997, Cleveland; abstract in Rubber Chem. Technol. 71, 146 (1998).

${ }^{24}$ ASTM D 5603-01, Classification for Rubber Compounding Materials-Recycled Vulcanizate Particulate Rubber, ASTM Book Stand. 09.01, p.821.

${ }^{25}$ P. P. Nicholas, Rubber Chem. Technol. 55, 1499 (1982).

${ }^{26}$ M. Myhre and D. A. MacKillop, paper\#21, presented at a meeting of the Rubber Division., ACS, Oct. 17-20, 1995, Cleveland; abstract in Rubber Chem. Technol. 69, 142 (1996). 
${ }^{27}$ S. Yamashita, Japan-USSR polym. Symp. (Proc. Eng) 1976, 355-364; Chem. Abstracts, 85, 34333f, (1976).

${ }^{28}$ D. S. Novotny (to Goodyear Tire \& Rubber Company) US 4, 104, 205 (1978).

${ }^{29}$ K. Baranwal, J. W. Rogers, P. M. Standley, paper \#39 presented at a meeting of the Rubber Division, ACS, Sept. 29-Oct. 2, 1998. Nashville; abstract in Rubber Chem. Technol. 72, 235 (1999).

${ }^{30}$ F. B. Menadue, Rubber Age 56, 511 (1945).

${ }^{31}$ D. F. Twiss, A. J. Hughes, P. H. Amphlett, Brit. 577,868 \& 578,482, 1946.

${ }^{32}$ STIK Polymers America Promotional Publication.

${ }^{33}$ K. K. Hon, F. Siesseger, B. C. Sekhar, S. W. Sin, paper \#55, presented at a meeting of the Rubber Division ACS, Oct. 17-20, 1995., Cleveland; abstract in Rubber Chem. Technol. 69, 151 (1996).

${ }^{34}$ R. Kohler and J. O’Neill, paper \#58, presented at a meeting of the Rubber Division, ACS, Oct. 8-11, 1995, Louisville; abstract in the Rubber Chem. Technol. 70, 162 (1997).

${ }^{35}$ R. Newell, Int. Rubber Conf., Manchester UK, 17-21, June 1996.

${ }^{36}$ D. De, B. Adhikari, S. Mait, J. Poly. Mate. 14, 333 (Dec. 1997).

${ }^{37}$ D. De, S. Maiti, B. Adhikari, J. Appl. Polym. Sci. 73, 2951 (1999).

${ }^{38}$ Y. Watabe, Y. Fuji, S. Anzai, J. Furukawa (to Bridgestone Tire Co.), US. 4,211,676 (July 8, 1980).

${ }^{39}$ M. Mouri, A. Usuki, N. Sato, (to Kabushiki Kaisha Toyota Chuo Kenky-usho) US. 5,672,630 (1977).

${ }^{40} \mathrm{M}$. Mouri, et al. as written, paper \#84 presented at a meeting of the Rubber Division, ACS, Apri, 13-16, 1999, Chicago; abstract in Rubber Chem, Technol. 72, 805 (1999).

${ }^{41}$ E. H. Cotton and R. A. Gibbons, US. 2,408,296,194 (Sept. 24, 1940).

${ }^{42}$ R. V. Le Beau (to Midwest Rubber Reclaiming) US. 2,423, 032 and 033 (June 24, 1947); 2, 363,873 (1945); 2, 372,584 (1945).

${ }^{43}$ H. E. Albert (to Firestone) U S. 2,605, 241 (Jul. 29, 1952).

${ }^{44}$ W. S. Cook (to Firestone) US. 2,560,050 (Jul. 10, 1951).

45 J. R. Lewis (to Hercules Powder Co.) US. 2,558,764 (Jul. 3, 1951).

${ }^{46}$ W. A. Hensley and H. E. Albert (to Firestone) US 2,686,162 (August 10, 1954).

${ }^{47}$ W. G. Kirby, L. E. Steinle (to U. S. Rubber Co.) U.S. 2,359,122 (Sept. 26, 1994).

${ }^{48}$ H. Hildibrant, Continental G-W, A. G., Ger. P 1,244,390, 1967; Chem. Abstracts, 70, 82835w, (1969).

49 A. I. Isayev (to University of Akron) U.S. 5,258,413 (Nov. 2, 1993). I. Isayev (to University of Akron) U.S. 5,284,625, (Feb. 8, 1994).

${ }^{50}$ A. I. Isayev, J. Chen, A. Tukachinsky, Rubber Chem. Technol. 68, 267 (1995).

${ }^{51} \mathrm{~V}$. Y. Levin et al. as written, paper \#57 presented at a meeting of the Rubber Division, ACS, Oct. 17-20, 1995, Cleveland; abstract in Rubber Chem. Technol. 69, 151 (1996).

${ }^{52}$ A. I. Isayev, S. H. Kim, V. Y. Levin, paper \#62 presented at a meeting of the Rubber Division, ACS, Oct, 8-11, 1996, Louisville; abstract in the Rubber Chem. Technol. 70, 163 (1997).

${ }^{53} \mathrm{M}$. Tapale, A. I. Isayev, paper\#83, presented at a meeting of the Rubber Division, ACS, Oct. 21-24, 1997, Cleveland; abstract in Rubber Chem. Technol. 71, 142 (1998).

${ }^{54}$ S. H. Kim, V. Y. Levin, A. I. Isayev, paper \#99, presented at a meeting of the Rubber Division, ACS, Oct. 21-24, 1997, Cleveland; abstract in Rubber Chem. Technol. 71, 141 (1998). 
55 S. H. Kim and A. I. Isayev, paper\#55, presented at a meeting of the Rubber Division, ACS, Sept. 29-Oct. 2, 1998, Nashville; abstract in Rubber Chem. Technol. 72, 241 (1999).

${ }^{56}$ M. Meysami, P. Mutyala, S. Zhu, and C. Tzoganakis. $72^{\text {nd }}$ Annual Technical Conference of the Society of Plastics Engineers: The Plastics Conference, ANTEC 2014; Las Vegas; United States; 28 April 2014 through 30 April 2014; Code 113016, 2, 1025.

${ }^{57}$ P. Mutyala, M. Meysami, S. Zhu, and C. Tzoganakis. $71^{\text {st }}$ Annual Technical Conference of the Society of Plastics Engineers 2013, ANTEC 2013; Cincinnati, OH; United States; 22 April 2013 through 24 April 20143; Code 105955. 2, 1224.

${ }^{58}$ P. Sutanto, F. L. Laksmana, F. Picchioni, and L. P. B. M. Janssen. Chem. Eng. Sci. 61, 6442 (2006).

${ }^{59}$ M. A. L. Verbruggen, L. van Der Does, J. W. M. Noordermeer, M. van Duin, and H. J. Manuel. Rubber Chem. Technol. 72, 731 (1999).

${ }^{60}$ M. Mouri, N. Sato, H. Okamato, M. Matsushita, H. Honda, K. Nakashima, K. Takeushi, Y. Suzuki, and M, Owaki, Int. Poly. Sci. \& Technol. 27, 17 (2000).

${ }^{61}$ K. Fukumori, M. Matsushita, H. Okamoto, N. Sato, Y. Suzuki, K. Takeuchi. Recycling Technology of Tire Rubber, J.S.A.F. Review.23, 259 (2002).

${ }^{62}$ F. Cavalieri, F. Padella, F. Cataldo, J. Appl. Polym. Sci. 90, 1631 (2003).

${ }^{63}$ M. Magini, F. Cavalieri, and F. Padella, Mater. Sci. Forum 386-388:263-268 (2002).

${ }^{64}$ S. Ostad Mohaved, A. Ansarifar, S. Karbalaee Nezhad, S. Atharyfar . Poly. Degrad. Stabil. 111, 114 (2015).

${ }^{65}$ M. Kojima, M. Tosaka, and Y. Ikeda, Green Chem. 6, 84 (2004).

${ }^{66}$ M. Kojima, M. Ogawa, and H. Mizoshima. Rubber Chem. Technol. 76, 957 (2003).

67 J. Kim, and J. Park, J. Appl. Polym. Sci. 72, 1543 (1999).

${ }^{68}$ K. Bredberg, M. Christiansson, M. Bellander, B. Stenberg, and A. Holst, Prog. Rubb. \& Plast. Technol. 17, 149 (2001).

${ }^{69}$ K. Jiang K, J. Shi, Y. Ge, R. Zou, P.Yao, X. Li, and L. Zhang. J. Appl. Polym. Sci. 127, 2397 (2013).

${ }^{70}$ J. Guangming, and Z. Suhe. J. Appl. Polym. Sci. 116, 2768 (2010).

${ }^{71}$ L. Mingchao, L. Xiaoxue, L. Shuangquan, and Z. Yanfang, Adv. Mat. Res. 554-556:181186 (2012).

${ }^{72}$ L. M. Lopez, A. B. Cosgrove, J. P. Hernandez Ortiz, and T. A. Osswald, Polym. Eng. Sci. 47, 675 (2007).

${ }^{73}$ V. Pistor, F. G. Ornaghi, R. Fiorio, A. J. Zattera, Thermochim Acta. 510, 93 (2010).

${ }^{74}$ T. A. Ozawa, Bulletin Chem. Soc. Jpn. 38, 1881 (1965).

${ }^{75}$ T. A. Ozawa, Bulletin Chem. Soc. Jpn. 39, 2071(1966).

${ }^{76}$ J. H. Flynn, and L. A. Wall, J. Res. Natl. Bur. Stand A Phys. Chem . 70, 487 (1966).

${ }^{77}$ M. Poletto, V. Pistor, M. Zeni, and A. J. Zattera, Poly. Degrad. Stabil. 96, 679 (2011).

${ }^{78}$ L. Núñez, F. Fraga, M. R. Nứñez, M. Villanueva, Polymer 41, 4635 (2000).

${ }^{79}$ L. Nu'ñez, M. Villanueva, M. R. Nu'ñez, and B. J. Rial, J. Appl. Polym. Sci. 92, 1199 (2004).

${ }^{80}$ A. I. Isayev, and B. Sujan, J. Elast. \& Plast. 38, 291 (2006).

${ }^{81}$ I. Han, C. B. Chung, and J. W. Lee, Rubber Chem. Technol. 73, 101 (2000).

${ }^{82}$ S. Ostad Movahed, A. Ansarifar, G. Zohuri, N. Ghaneie, and Y. Kermany,. J. Elast. \& Plast. Published on line November 13, 2014.

${ }^{83}$ E. Thostenson, T. Chou, Composites part A 30, 1055 (1999).

${ }^{84}$ D. E. Clark, D. C. Folz, J. K. West, Mater. Sci. Eng. A 287, 153 (2000). 
${ }^{85}$ V. Pistor, and A. Zattera, J. Elast. \& Plast. 46, 69 (2014).

${ }^{86}$ P. Sutanto, F. Picchioni, and L. P. B. M. Janseen. Chem. Eng. Sci. 61, 7077 (2006).

${ }^{87}$ S. Ostad Movahed, A. Ansarifar, S. Karbalaee Nezhad, and S. Athary Far, Prog. Rubb. Plast, \& Recyl. 31, 87 (2015).

${ }^{88}$ S. Wolff, Rubber Chem. Technol. 66, 163 (1993).

${ }^{89}$ F. P. Baldwin, and G. Verstrate, Rubber Chem. Technol. 45, 709 (1972).

90 ASTM designation, Standard Test Method for Determination of Percent Devulcanization of Crumb Rubber Based on Crosslink Density: ASTM D6814-02;2008.

${ }^{91}$ A. Bani, G. Polacco, and G. Gallone. J. Appl. Polym. Sci. 120, 2904 (2011).

${ }^{92}$ M. M. Horikx. J Polym. Sci., 19, 445 (1956).

${ }^{93}$ H. Liang, J. M. Hardy, D. Rodrigue, and J. Brisson, Rubber Chem. Technol. 87, 538 (2014).

${ }^{94}$ M. D. Ellul, A. H. Tsou, and W. Hu, Polymer 45, 3351 (2004).

${ }^{95}$ M. Aluas, and C. Filip, Solid State Nucl. Magn. Reson. 27, 165 (2005).

${ }^{96}$ V. M. Litvinov, and W. Barendswaard, Rubber Chem. Technol. 71, 105 (1998).

${ }^{97}$ V. M. Livinov, Macromolecules 39, 8727 (2006).

${ }^{98}$ V. M. Litvinov, R. A. Orza, M. Klupel, Van Duin, P. C. M. M. Magusin, Macromolecules 44, 4887 (2011).

99 D. Moldovan, R. Fechete, D. E. Demco, E. Culea, B. Blumich, V. Hermann, and M. Heinz, J. Magn. Reson. 208, 156 (2011).

${ }^{100}$ R. A. Ozra, P. C. M. M. Magusin, V. M. Litvinov, M. van Duin, M. A. Michels, J Macromol symp. 230, 144 (2005).

${ }^{101}$ S. Bhattacharjee, H. Bender, and D. Padliya, Rubber Chem. Technol. 76, 1057 (2003).

${ }^{102}$ Z. Niloofar Kalantar, M. Rehan Karim, and A. Mahrez, Constr. Build. Mater. 33, 55 (2012).

${ }^{103}$ H. Nabil, H. Ismail, and A. R. Azura, Mater. \& Des. 50, 27 (2013).

${ }^{104}$ H. Nabil, and H. Ismail, Mater. \& Des. 56, 1057 (2014).

${ }^{105}$ H. Nabil, and H. Ismail, Int. J. Polym. Anal. Ch. 014;19:159 (2014).

${ }^{106}$ H. Nabil, H. Ismail, and A. R. Azura, Mater. \& Des. 53, 651 (2014).

${ }^{107}$ H. Nabil, H.Ismail, and A. R. Azura, Polym. Testing 32, 385 (2013).

${ }^{108}$ H. Nabil, H, Ismail, and A. R. Azura, Iran Polym. J. 23, 37 (2014).

${ }^{109}$ H. Nabil, H. Ismail, and A. R. Azura, Polym. Testing 32, 631 (2013).

${ }^{110}$ P. Mahallati, and D. Rodrigue, Int Polym. Proc. 29, 280 (2014).

${ }^{111}$ H. Ismail, S. Ishak, and Z. A. A. Hamid, J. Vinyl. Addit. Tech:Published online 9 June, 2014.

112 C. Wang, Q. Xie, and H. Bian, Key Eng. Mat. 501, 311 (2012).

${ }^{113}$ V. Pistor, F. G. Ornaghi, R. Fiorio, and A. J. Zattera. J. Elast. \& Plast. 42, 417 (2010).

${ }^{114}$ G. C. Santos, D. M. Carmo, C. G. F. Rezende, A. J. Zattera, M. G. Oliveira, and P. J. Oliveira, J. Appl. Polym. Sci. 122, 948 (2011).

115 A. Jalilvand, I. Ghasemi, M. Karrabi, and H. Azizi, Iran Polym. J. 16, 637 (2007).

${ }^{116}$ H. Tan and A. I. Isayev. Rubber Chem. Technol. 81, 138 (2008).

117 A. I. Isayev, T. Liang, and T. M. Lewis. Rubber Chem. Technol. 87, 86 (2014).

${ }^{118}$ A. Macsiniuc, A. Rochette, and D. Rodrigue. Prog. Rubb. Plast, \& Recy. Technol., 26, 51 (2010).

${ }^{119}$ A. Macsiniuc, A. Rochette, and D. Rodrigue. Prog. Rubb. Plast \& Recy. Technol. 28, 43 (2012).

${ }^{120}$ H. Liang, J-M. Hardy, D. Rodrigue, and J. Brisson. Rubber Chem. Technol. 87, 538 (2014). 
${ }^{121}$ C. Jacob, A. K. Bhowmick, P. P. De, and S. K. De. Rubber Chem. Technol. 76, 36 (2003).

${ }^{122}$ M. Myhre, S. Saiwari, W. Dierkes, and J. Noordermeer. Rubber Chem. Technol. 85, 408 (2012). 


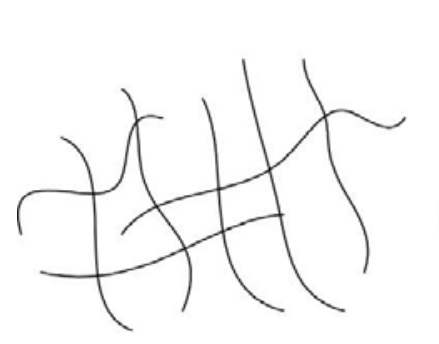

Raw rubber

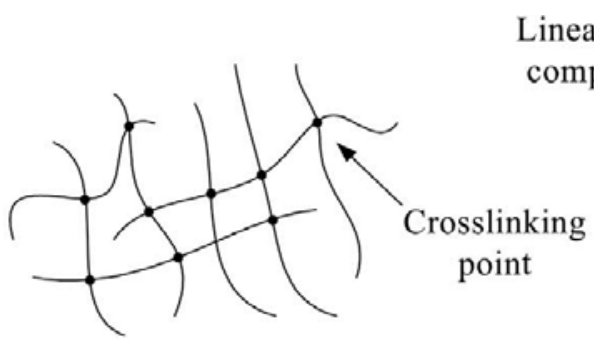

Vulcanized rubber
Linear chain

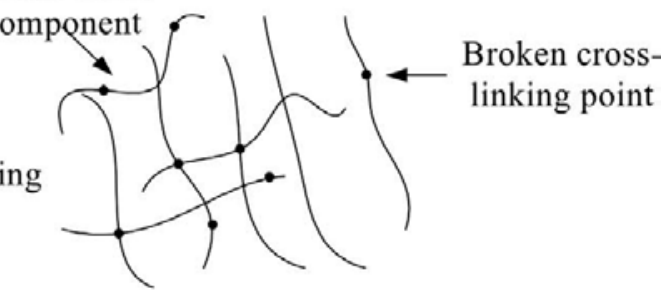

Devulcanized rubber

FIG. 1.- Difference between the molecular structures of virgin raw rubber, vulcanized rubber, and devul canized rubber. ${ }^{4}$

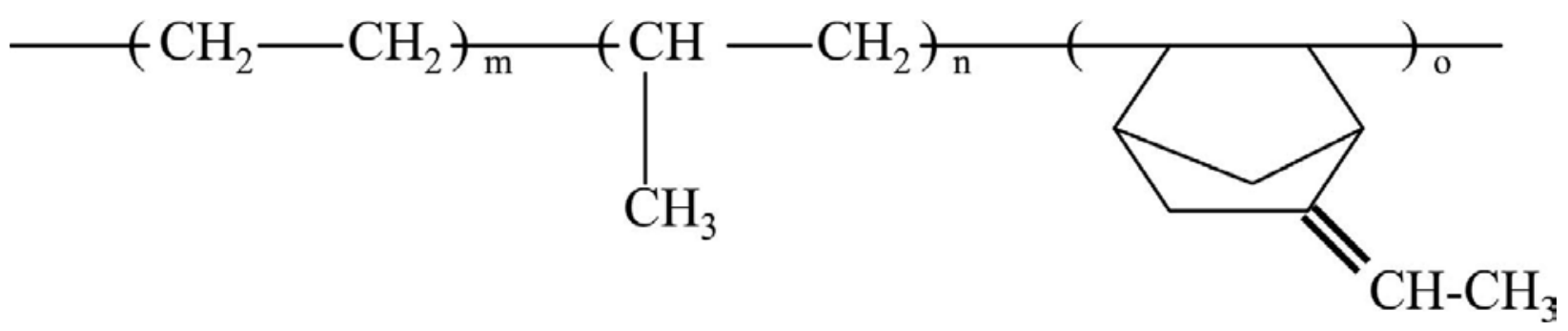

FIG. 2.-Composition and molecular structure of ethylene-propylene-diene rubber (EPDM). ${ }^{6}$

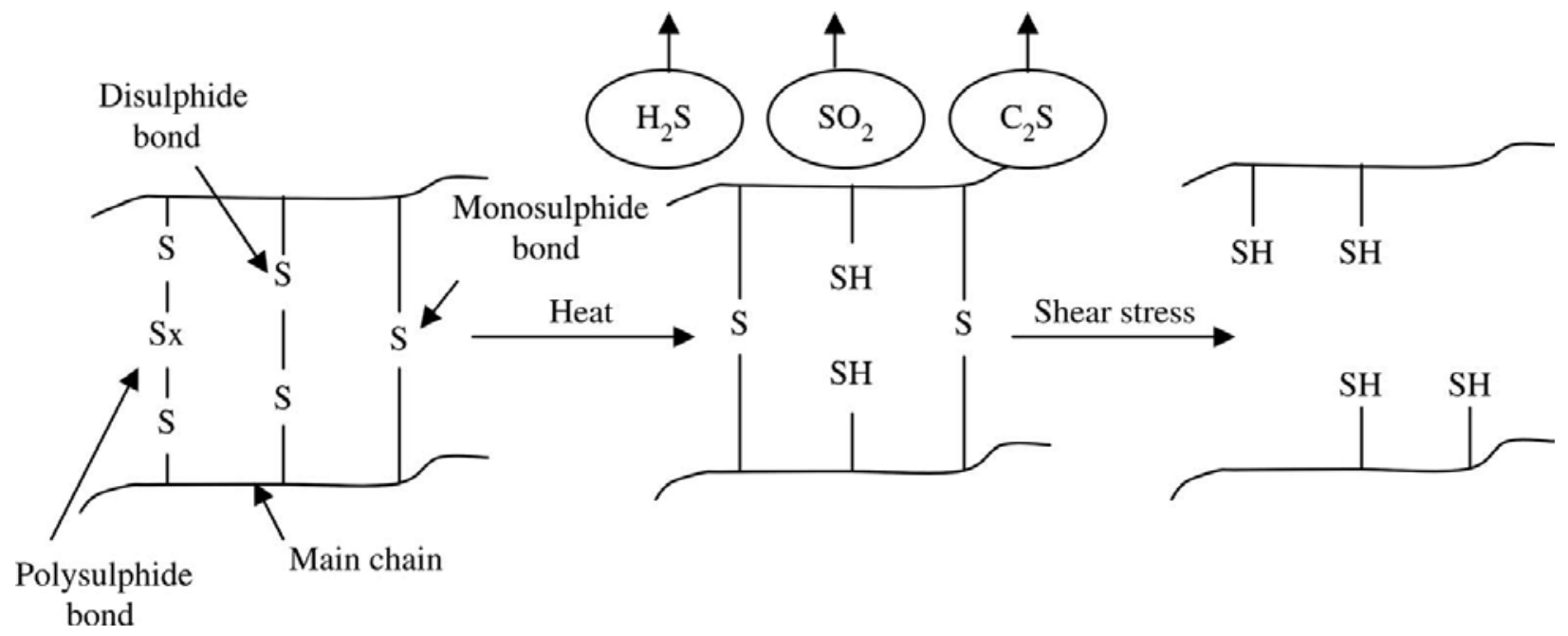

FIG. 3. - A general devulcanization reaction mechanism. ${ }^{60}$ 


\section{Elastic constant (relative value)}

(a)

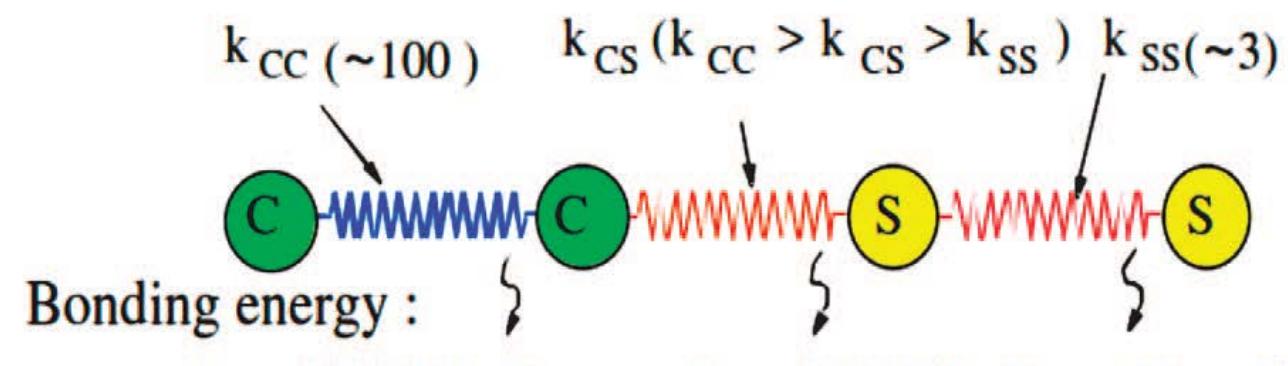

$$
\mathrm{E}_{\mathrm{CC}}: 370 \mathrm{~kJ} / \mathrm{mol} \quad \mathrm{E}_{\mathrm{CS}}: 310 \mathrm{~kJ} / \mathrm{mol} \quad \mathrm{E}_{\mathrm{SS}}: 270 \mathrm{~kJ} / \mathrm{mol}
$$

(b)

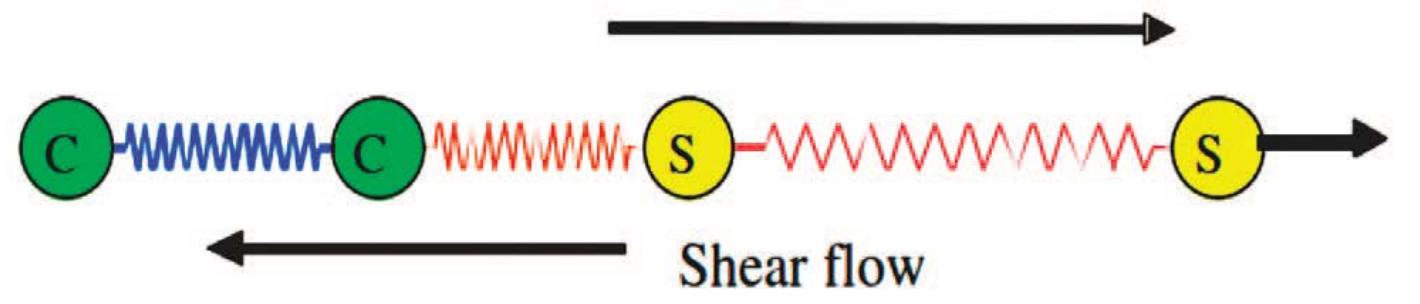

FIG. 4.-Breakages of crosslinks in high shear flow: (a) model for the network chain; (b) deformation of the network chain (particularly S-S bonds) by shearing. ${ }^{61}$

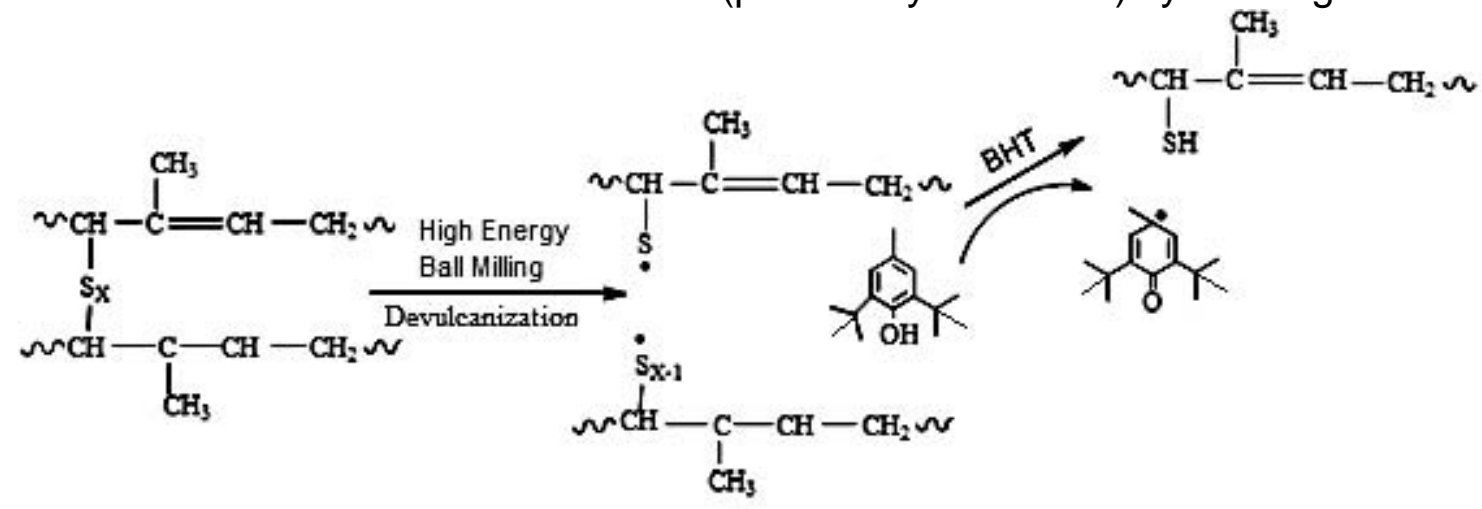

$\mathrm{X}=1$ monosulfidic crosslink, $\mathrm{X}=2$ :disulfidic crosslink, $\mathrm{X} \geq 3$.polysulfidic crosslink

FIG. 5.-Capture of the macro-radical products in the presence of $\mathrm{BHT}{ }^{62,63}$ 


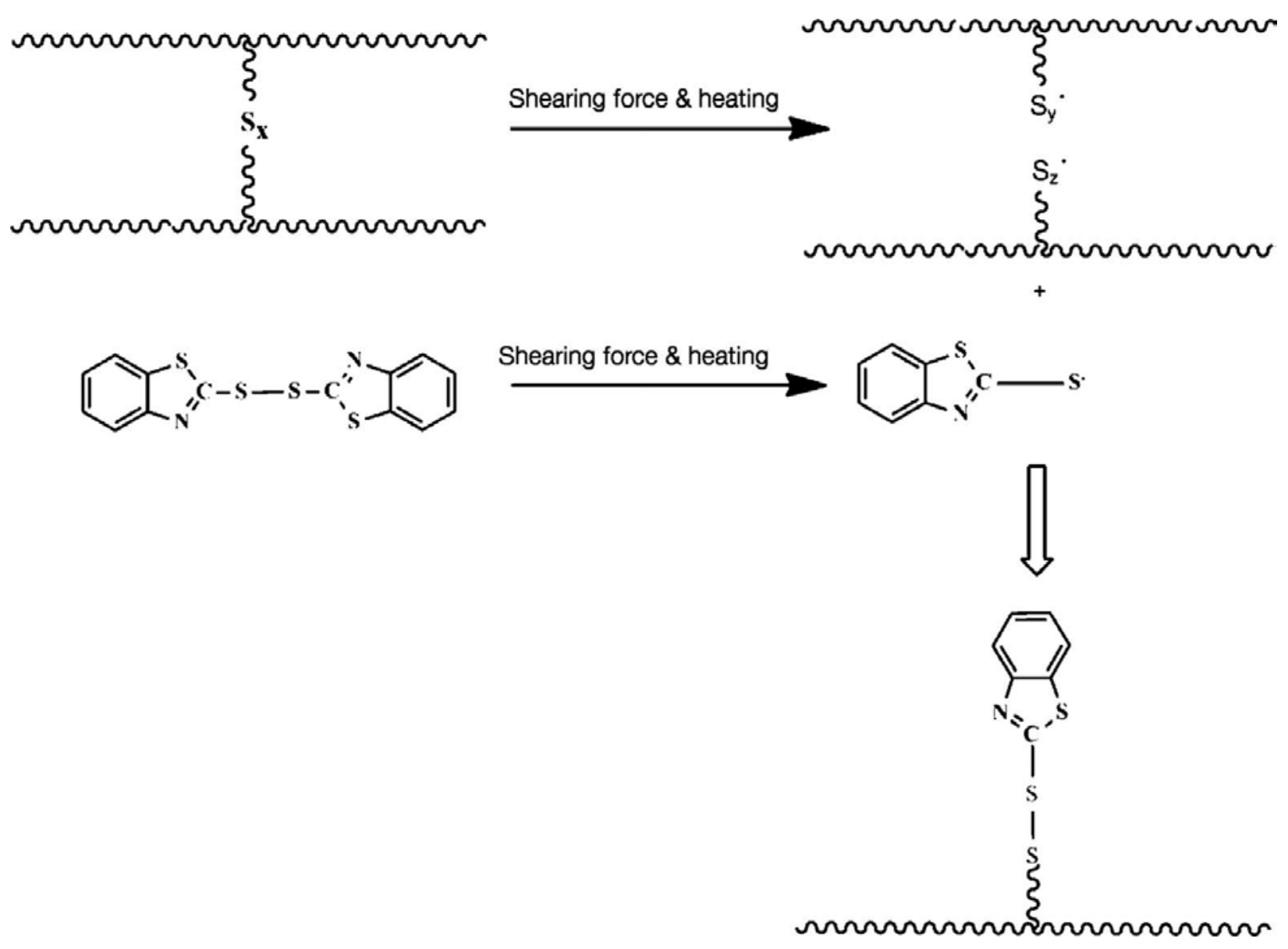

FIG. 6. - Devulcanization mechanism by combined heat, shearing force, and devulcanizing chemical agent 2-mercaptobenzothiazole disulfide (MBTS). ${ }^{64}$

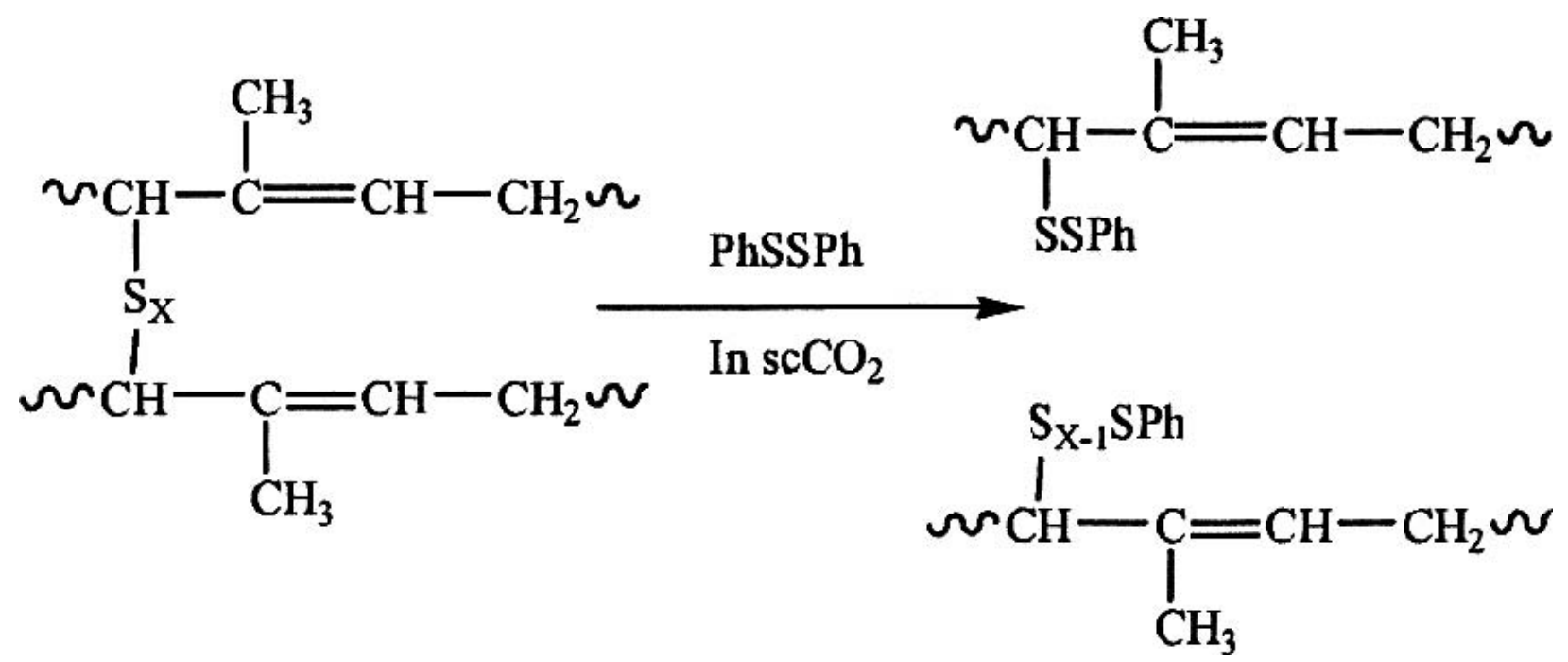

FIG. 7. - Mechanism of crosslink cleavage reaction using diphenyl disulfide in scCO2. ${ }^{65,66}$ 


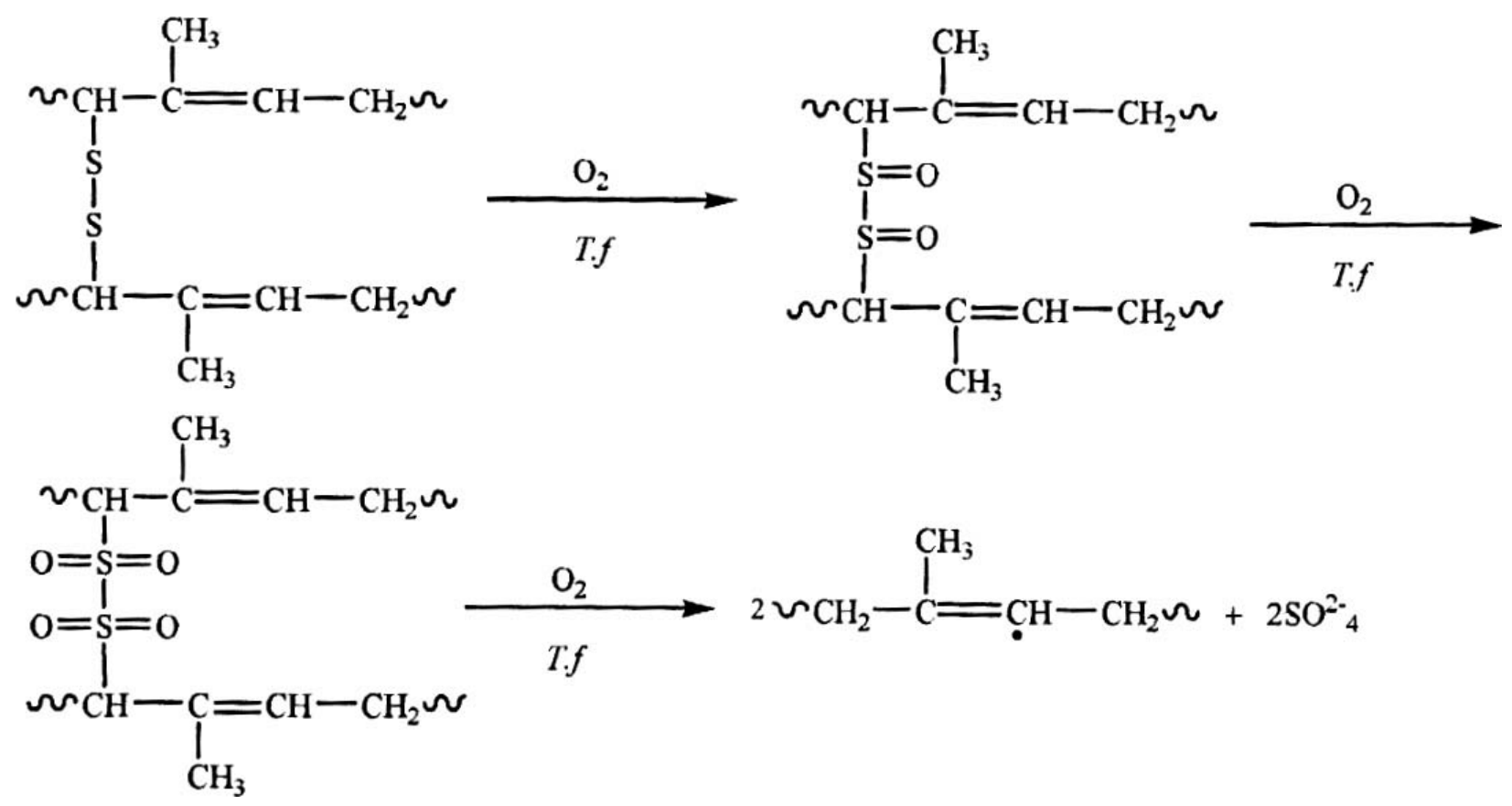

Fig. 8.-Mechanism of devulcanization by T.ferrooxidans. ${ }^{70}$

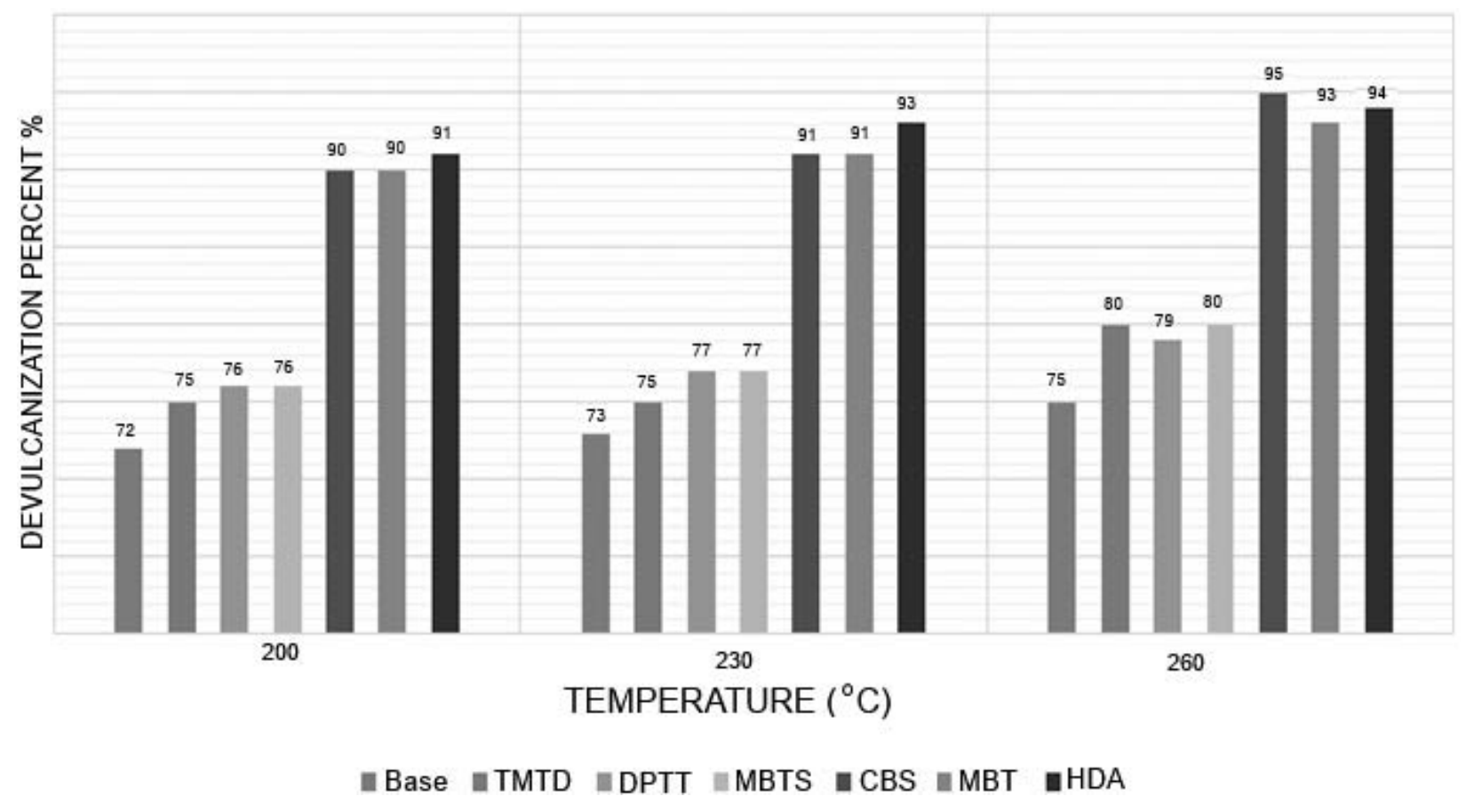

Fig. 9.-Comparison of the devul canization percentage of the rubber compounds as a function of devulcanization temperature. ${ }^{82}$ 


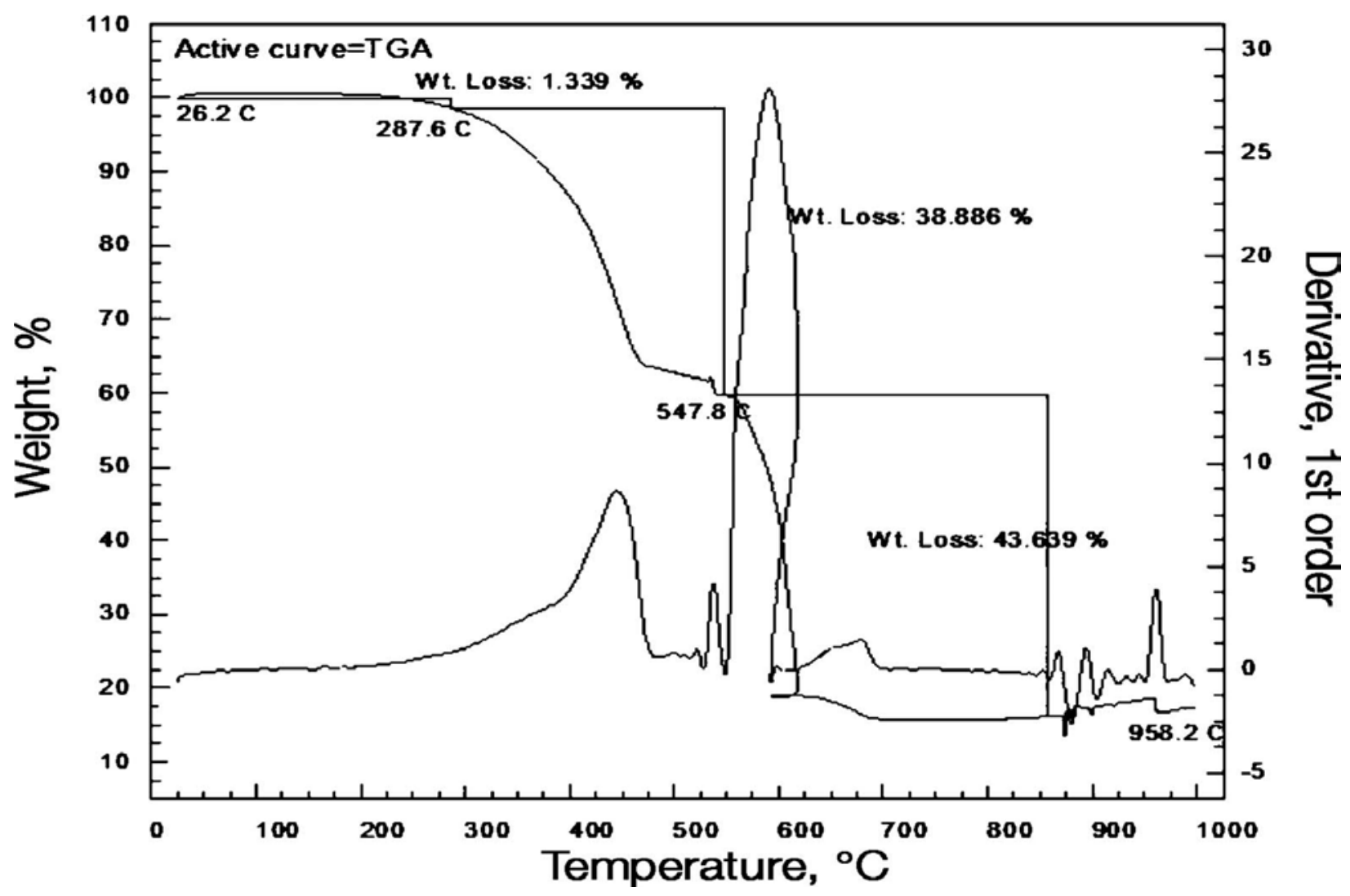

FIG. 10.-TGA traces of a typical automotive EPDM rubber waste powder. ${ }^{64,82,87}$

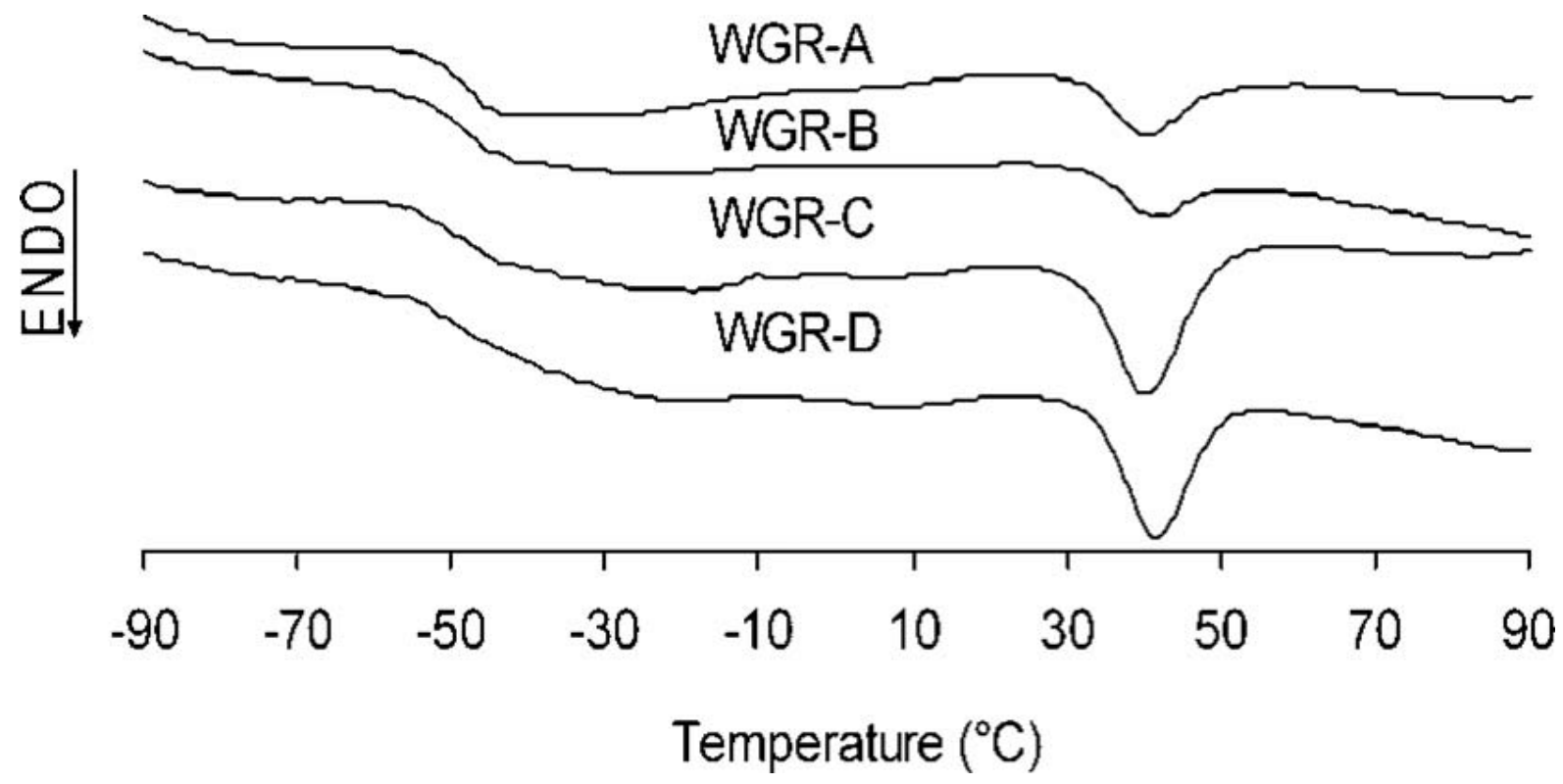

FIG. 11.-Differential scanning cal orimetry endotherms of some selected samples. Comparison of EPDM waste ground rubber samples. ${ }^{93}$ 